
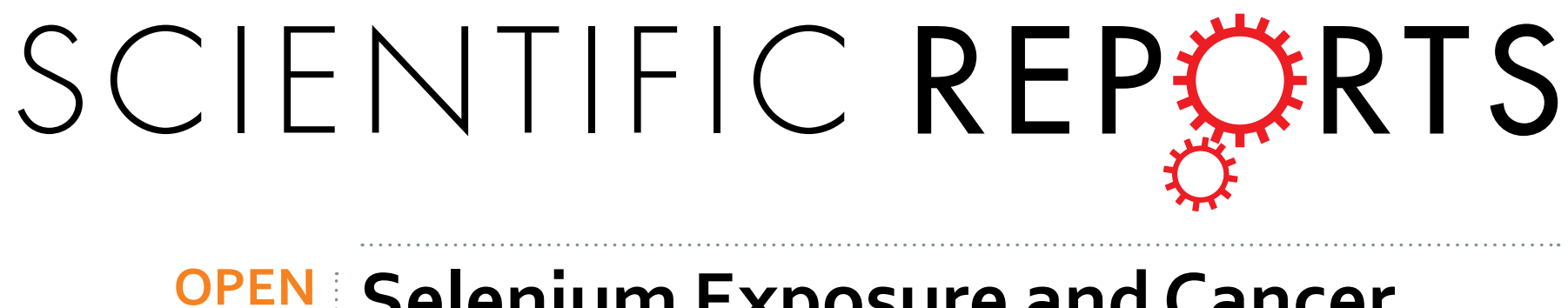

\title{
Selenium Exposure and Cancer Risk: an Updated Meta-analysis and Meta-regression
}

Received: 01 October 2015

Accepted: 08 December 2015

Published: 20 January 2016

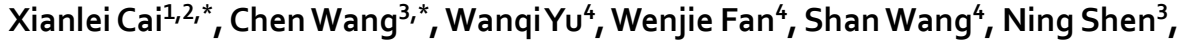 \\ Pengcheng $\mathrm{Wu}^{3}$, Xiuyang $\mathrm{Li}^{1,4}$ \& Fudi Wang ${ }^{5}$
}

The objective of this study was to investigate the associations between selenium exposure and cancer risk. We identified 69 studies and applied meta-analysis, meta-regression and dose-response analysis to obtain available evidence. The results indicated that high selenium exposure had a protective effect on cancer risk (pooled $\mathrm{OR}=0.78 ; 95 \% \mathrm{Cl}: 0.73-0.83$ ). The results of linear and nonlinear dose-response analysis indicated that high serum/plasma selenium and toenail selenium had the efficacy on cancer prevention. However, we did not find a protective efficacy of selenium supplement. High selenium exposure may have different effects on specific types of cancer. It decreased the risk of breast cancer, lung cancer, esophageal cancer, gastric cancer, and prostate cancer, but it was not associated with colorectal cancer, bladder cancer, and skin cancer.

Selenium (Se) is an essential trace element having considerable and particular functions for human health because it is genetically encoded for which incorporation into proteins, as the constitutive part of selenocysteine, the $21^{\text {st }}$ amino acid $^{1}$. Most se-proteins have been shown to have a wide range of pleiotropic effects, ranging from antioxidant to anti-inflammatory effects ${ }^{2}$, particularly the families of glutathione peroxidases (GPxs) and thioredoxin reductases (TrxRs) ${ }^{1}$, but their precise mechanism are not understood absolutely currently. Despite the scarce knowledge of mechanism, a large number of laboratory and ecologic researches focused on the associations between selenium and human health have been completed, showing that Se is associated with several human diseases including cardiovascular disease $\mathrm{s}^{3-5}$, central nervous system disease ${ }^{6}$, diabetes mellitus ${ }^{7-10}$, and cancer, but the results are inconsistent.

We can see worldwide debates on the relation between selenium and cancer risk. Observational studies and randomized controlled trials suggest different effects in human. A new meta-analysis ${ }^{11}$ published in Cochrane 2014 described the association between selenium and cancer prevention, and this article tended to analyze the effect of selenium supplement based on random controlled trials. There are other similar meta-analyses have been published, few of them established dose-response or beneficial range of selenium exposure associated with the risk reduction or determined the shape of dose-response curve to find whether it is a linear relation, saturation or U-shaped curve relation between selenium exposure level and cancer risk. On the other hand, numerous new studies have been reported in recent years, and we think it is meaningful to conduct an updated meta-analysis including different types of cancer to provide comprehensive evidence and clarify the shape of dose-response association between selenium status and cancer risk.

\section{Methods}

Search strategy. We carried out a systematic search for articles which described the relations between selenium and cancer risk in the medical and biologic databases (Medline 1980-March 2014, via Pubmed; Embase 1980-March 2014; Science Citation Index, Web of Science 1980- March 2014; CAB Health 1980- March 2014), using a comprehensive list of selenium/ selenium supplement/ serum/plasma selenium/ toenail selenium/ antioxidant/ minerals And cancer/ breast cancer/ lung cancer/ esophageal cancer/ gastric/stomach cancer/ colorectal cancer/ bladder cancer/ prostate cancer/skin cancer). We also searched references of relevant studies and reviews

${ }^{1}$ Institute of Environmental Medicine, Zhejiang University, P.R.China. ${ }^{2}$ Ningbo Medical Treatment Center Lihuili Hospital, P.R.China. ${ }^{3}$ Department of Clinic Medicine, Zhejiang University, Hangzhou, P.R.China. ${ }^{4}$ Department of Epidemiology \& Biostatistics, Zhejiang University, Hangzhou, P.R.China. ${ }^{5}$ Department of Toxicology \& Nutrition, Zhejiang University, Hangzhou, P.R.China. *These authors contributed equally to this work. Correspondence and requests for materials should be addressed to X.L. (email: lixiuyang@zju.edu.cn) 


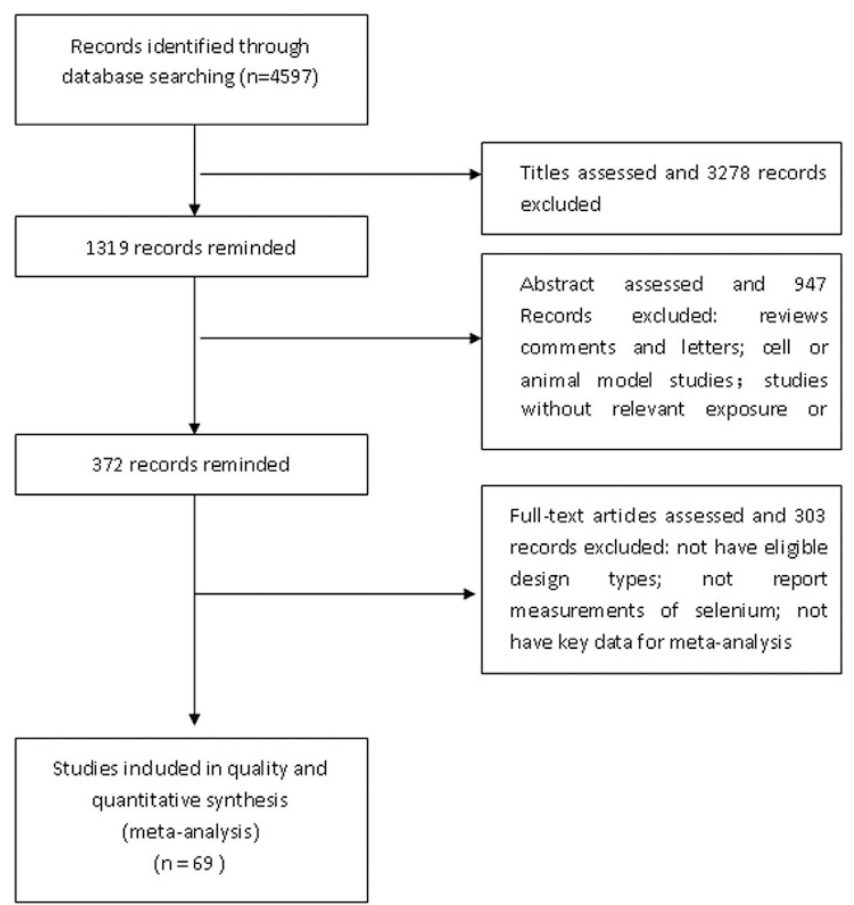

Figure 1. Flowchart of search strategy.

to identify works which were not found in the database search. The first two authors (Xianlei Cai and Chen Wang) conducted the search work (as shown in Fig. 1)

Inclusion and exclusion criteria. Inclusion criteria were as follows: (1) was a randomized controlled trial, cohort or case-control study; (2) regarded selenium as baseline exposure, and cancer event (including incidence and mortality) as outcome; (3) were original works in English language which were published and indexed from January 1980 to March 2014; (4) had key date for meta-analysis or dose-response analysis.

Exclusion criteria were as follows: (1) was not involved with exposure-response associations between selenium and cancer risk; (2) cytological studies, animal studies, reviews, comments, abstracts and reviews; (3) low quality articles.

Data extraction. All the data were extracted independently by three reviewers (Xianlei Cai, Chen Wang and Ning Shen) with a standardized data extraction form. The characteristics of the identified works were extracted as follows: first author name, year of publication, study country, design (RCT, cohort or case-control), number of subject (we extracted number of selenium exposure group and placebo group respectively from RCT studies, number of cohort participants from cohort studies, and number of case group plus control group from case-control studies), number of cases, age (mean or ranger), participants (men, women, both gender combined or special participants described in original studies), follow-up (year), Measurements of selenium (serum/plasma selenium, toenail selenium or selenium supplement), type of cancer, outcome, and estimates (odds ratio (OR), relative risk (RR) or hazard ratio (HR) at the highest compared with the lowest selenium exposure, with 95\% confidence interval (CI)); Table 1 presents the summary data of each identified work in our meta-analysis.

Quality assessment. We applied the Newcastle-Ottawa scale ${ }^{12,13}$ to assess the quality of the cohort and case-control studies. In this scale, one article was assessed on three perspectives: selection, comparability, outcome by using a "star system". The maximum score was nine stars. We simply regarded scores of 0-3 stars as low quality, scores of 4-6 stars as moderate quality, and scores of 7-9 stars as high quality. According to RCTs, we used the Cochrane collaboration's tool ${ }^{14}$ for assessing risk of bias from six domains: selection bias, performance bias, detection bias, attrition bias, reporting bias and other bias. Results were presented as low risk of bias, unclear risk of bias or high risk of bias.

Statistical analyses. We extracted the multivariate-adjusted RRs, HRs or ORs and 95\% confidence interval (CI) from original works. If some studies only provided $2 \times 2$ table data, we calculated the responding ORs. We considered these estimates as ORs when took those studies with different designs into account, for RRs and HRs were assumed to be the accurate estimates of ORs. Meta-regression analysis was conducted to figure out whether the associations between selenium exposure and cancer risk were influenced by some covariates (exposure modes, area and design), and we could recognize the influence factor with a positive meta-regression coefficient $(P \leq 0.05)$. We used Greenland and Longnecker ${ }^{15}$ method to conduct study-specific dose-response analyses based on the estimates of each category of plasma/serum selenium (ug/L), toenail selenium (ug/g) and selenium supplement $(\mathrm{ug} / \mathrm{d})$ respectively. We used mean or median of selenium exposure for each category when it was 


\begin{tabular}{|c|c|c|c|c|c|c|c|c|c|c|c|}
\hline Study & Country & Design & Subject & Case & age & Gender & Follow-up & $\begin{array}{c}\text { Measurements of } \\
\text { selenium }\end{array}$ & $\begin{array}{l}\text { Type of } \\
\text { cancer }\end{array}$ & OR(95\%CI) & Quality sore \\
\hline \multicolumn{12}{|c|}{ Not site specific cancer } \\
\hline Bleys J(2008) & USA & cohort & 13887 & 457 & $20-90$ & $\mathrm{M}$ and $\mathrm{F}$ & $12 \mathrm{Y}$ & Serum selenium & All cancer & $0.69(0.53,0.90)$ & 9 \\
\hline $\begin{array}{l}\text { Akbaraly } \\
\text { NT(2005) }\end{array}$ & France & cohort & 1387 & 45 & $59-71$ & $\mathrm{M}$ and $\mathrm{F}$ & $9 \mathrm{Y}$ & Serum selenium & All cancer & $0.56(0.41,0.76)$ & 8 \\
\hline \multirow[t]{2}{*}{ Kornitzer M(2004) } & Belgium & $\begin{array}{c}\text { nested } \\
\text { case-control }\end{array}$ & 539 & 139 & $25-74$ & Men & $10 \mathrm{Y}$ & Serum selenium & All cancer & $0.45(0.27,0.77)$ & 9 \\
\hline & & & 195 & 50 & & Women & & & & $1.43(0.63,3.33)$ & \\
\hline Ujiie S(2002) & Japan & cohort & 5019 & 2707 & N/A & $\mathrm{M}$ and $\mathrm{F}$ & $5 \mathrm{Y}$ & Serum selenium & All cancer & $0.40(0.35,0.46)$ & 7 \\
\hline $\begin{array}{l}\text { Persson-Moschos } \\
\text { ME(2000) }\end{array}$ & Sweden & $\begin{array}{c}\text { nested } \\
\text { case-control }\end{array}$ & 903 & 302 & $\begin{array}{l}\text { middle } \\
\text { age }\end{array}$ & Men & $6 \mathrm{Y}$ & Serum selenium & All cancer & $0.19(0.04,0.83)$ & 8 \\
\hline \multicolumn{12}{|l|}{ Breast cancer } \\
\hline Harris H R(2012) & Swedish & cohort & 66651 & 3146 & mean 65 & Women & $9 \mathrm{Y}$ & Diet selenium & Breast cancer & $0.69(0.52,0.92)$ & 9 \\
\hline \multirow[t]{2}{*}{ Pan S Y(2011) } & Canada & case-control & 4824 & 866 & $20-76$ & $\begin{array}{c}\text { Premen- } \\
\text { opausal }\end{array}$ & $\mathrm{N} / \mathrm{A}$ & Diet selenium & Breast cancer & $1.10(0.75,1.61)$ & 8 \\
\hline & & & 4824 & 1496 & & $\begin{array}{c}\text { Postmen- } \\
\text { opausal }\end{array}$ & & & & $1.09(0.84,1.43)$ & \\
\hline Rejali L(2007) & Malaysia & $\begin{array}{c}\text { matched } \\
\text { case-control }\end{array}$ & 124 & 62 & mean 49 & Women & $\mathrm{N} / \mathrm{A}$ & Serum selenium & Breast cancer & $0.89(0.84,0.94)$ & 8 \\
\hline Cui Y (2007) & USA & $\begin{array}{c}\text { Nested } \\
\text { case-control }\end{array}$ & 304 & 252 & $\mathrm{~N} / \mathrm{A}$ & Women & N/A & $\begin{array}{l}\text { Breast tissue } \\
\text { selenium }\end{array}$ & Breast cancer & $1.06(0.70,1.62)$ & 9 \\
\hline Singh P (2005) & India & case-control & 320 & 160 & mean 45 & Women & $\mathrm{N} / \mathrm{A}$ & Serum selenium & Breast cancer & $0.93(0.72,1.22)$ & 8 \\
\hline \multirow[t]{2}{*}{ Mannisto S(2000) } & Finland & case-control & 280 & 112 & $25-75$ & $\begin{array}{c}\text { Premen- } \\
\text { opausal }\end{array}$ & N/A & Toenail & Breast cancer & $0.90(0.30,2.70)$ & 9 \\
\hline & & & 442 & 177 & & $\begin{array}{c}\text { Postmen- } \\
\text { opausal }\end{array}$ & & selenium & & $0.60(0.30,1.30)$ & \\
\hline Ghadirian P(2000) & Canada & case-control & 1102 & 414 & N/A & Women & $\mathrm{N} / \mathrm{A}$ & Toenail selenium & Breast cancer & $0.72(0.40,1.31)$ & 8 \\
\hline Dorgan J F(1998) & USA & $\begin{array}{c}\text { nested } \\
\text { case-control }\end{array}$ & 315 & 105 & mean 58 & Women & N/A & Serum selenium & Breast cancer & $0.90(0.40,1.80)$ & 9 \\
\hline Strain J J(1997) & $\begin{array}{l}\text { Northern } \\
\text { Ireland }\end{array}$ & case-control & 204 & 99 & mean 62 & $\begin{array}{c}\text { Postmen- } \\
\text { opausal }\end{array}$ & N/A & Toenail selenium & Breast cancer & $0.75(0.35,1.57)$ & 8 \\
\hline van T V P(1996) & Europe & case-control & 605 & 266 & $50-74$ & $\begin{array}{c}\text { Postmen- } \\
\text { opausal }\end{array}$ & N/A & Toenail selenium & Breast cancer & $0.96(0.63,1.47)$ & 8 \\
\hline $\begin{array}{l}\text { van den Brandt P } \\
\mathrm{A}(1994)\end{array}$ & Netherlands & cohort & 62537 & 355 & $55-69$ & $\begin{array}{c}\text { Postmen- } \\
\text { opausal }\end{array}$ & $3.3 \mathrm{Y}$ & Toenail selenium & Breast cancer & $0.84(0.55,1.27)$ & 9 \\
\hline Hardell L(1993) & Sweden & case-control & 632 & 441 & $20-84$ & Women & N/A & Serum selenium & Breast cancer & $0.33(0.17,0.64)$ & 7 \\
\hline \multirow[t]{3}{*}{ van T V P(1990) } & Netherlands & case-control & 371 & 133 & $25-64$ & Women & N/A & Diet selenium & Breast cancer & $0.63(0.29,1.25)$ & 9 \\
\hline & & & & & & & & Serum selenium & & $0.50(0.23,1.11)$ & \\
\hline & & & & & & & & Toenail selenium & & $0.91(0.48,1.67)$ & \\
\hline Knekt $\mathrm{P}(1990)$ & Finland & cohort & N/A & 48 & $15-99$ & women & N/A & Serum selenium & Breast cancer & $1.03(0.43,2.50)$ & 8 \\
\hline \multicolumn{12}{|l|}{ Lung cancer } \\
\hline Jaworska K(2013) & Poland & case-control & 172 & 86 & $\begin{array}{c}\text { mean } \\
61.6\end{array}$ & $\mathrm{M}$ and $\mathrm{F}$ & $\mathrm{N} / \mathrm{A}$ & Serum selenium & Lung cancer & $0.10(0.03,0.34)$ & 8 \\
\hline Jablonska E(2008) & Poland & case-control & 612 & 325 & $30-78$ & $\mathrm{M}$ and $\mathrm{F}$ & N/A & Serum selenium & Lung cancer & $1.21(0.67,2.20)$ & 8 \\
\hline $\begin{array}{l}\text { Gromadzinska } \\
J(2003)\end{array}$ & Poland & case-control & 362 & 152 & $43-78$ & $\mathrm{M}$ and $\mathrm{F}$ & $\mathrm{N} / \mathrm{A}$ & Serum selenium & Lung cancer & $0.33(0.18,0.60)$ & 8 \\
\hline Hartman TJ(2002) & Finland & $\begin{array}{c}\text { Nested } \\
\text { case-control }\end{array}$ & 500 & 250 & $50-69$ & men & N/A & Toenail selenium & Lung cancer & $0.20(0.09,0.44)$ & 9 \\
\hline $\begin{array}{l}\text { Goodman } \\
\text { GE(2001) }\end{array}$ & USA & case-control & 712 & 356 & $45-74$ & men & $\mathrm{N} / \mathrm{A}$ & Serum selenium & Lung cancer & $1.20(0.77,1.88)$ & 9 \\
\hline $\begin{array}{l}\text { Ratnasinghe } \\
D(2000)\end{array}$ & China & $\begin{array}{c}\text { nested } \\
\text { case-control }\end{array}$ & 324 & 108 & $35-74$ & men & $6 \mathrm{Y}$ & Serum selenium & Lung cancer & $1.20(0.60,2.40)$ & 9 \\
\hline Knekt P(1998) & Finland & $\begin{array}{c}\text { nested } \\
\text { case-control }\end{array}$ & 285 & 95 & mean 57 & $\mathrm{M}$ and $\mathrm{F}$ & $19 \mathrm{Y}$ & Serum selenium & Lung cancer & $0.41(0.17,0.94)$ & 9 \\
\hline Garland M(1995) & USA & $\begin{array}{c}\text { nested } \\
\text { case-control }\end{array}$ & 94 & 47 & $30-55$ & women & $41 \mathrm{M}$ & Toenail selenium & Lung cancer & $1.95(0.41,9.28)$ & 8 \\
\hline Kabuto, M(1994) & Japan & case-control & 197 & 77 & $59-60$ & $\mathrm{M}$ and $\mathrm{F}$ & $13 \mathrm{Y}$ & Serum selenium & Lung cancer & $0.56(0.20,5.88)$ & 8 \\
\hline $\begin{array}{l}\text { van den Brandt } \\
\text { PA(1993) }\end{array}$ & Netherlands & cohort & 3345 & 384 & $55-69$ & $\mathrm{M}$ and $\mathrm{F}$ & $3.3 \mathrm{Y}$ & Toenail selenium & Lung cancer & $0.40(0.27,0.97)$ & 9 \\
\hline Knekt P(1990) & Finland & cohort & $\mathrm{N} / \mathrm{A}$ & 153 & $15-99$ & men & N/A & Serum selenium & Lung cancer & $0.66(0.37,1.19)$ & 8 \\
\hline $\begin{array}{l}\text { Lippman } \\
\text { SM(2009) }\end{array}$ & $\begin{array}{l}\text { USA, Canada, } \\
\text { Puerto Rico }\end{array}$ & RCT & P:8696,e:8752 & P:67,e: 75 & $\geq 50$ & men & $5.46 \mathrm{Y}$ & $\begin{array}{c}\text { Selenium supple- } \\
\text { ment }\end{array}$ & Lung cancer & $1.12(0.73,1.72)$ & $\begin{array}{c}\text { low risk of } \\
\text { bias }\end{array}$ \\
\hline Clark LC(1996) & USA & RCT & P:659, e: 653 & P:35, e: 13 & mean 63 & $\mathrm{M}$ and $\mathrm{F}$ & $6.4 \mathrm{Y}$ & \begin{tabular}{|c|} 
Selenium supple- \\
ment
\end{tabular} & Lung cancer & $0.56(0.31,1.01)$ & $\begin{array}{c}\text { low risk of } \\
\text { bias }\end{array}$ \\
\hline \multicolumn{12}{|l|}{ Esophageal cancer } \\
\hline \multicolumn{12}{|l|}{ Continued } \\
\hline
\end{tabular}




\begin{tabular}{|c|c|c|c|c|c|c|c|c|c|c|c|}
\hline Study & Country & Design & Subject & Case & age & Gender & Follow-up & $\begin{array}{c}\text { Measurements of } \\
\text { selenium }\end{array}$ & $\begin{array}{l}\text { Type of } \\
\text { cancer }\end{array}$ & OR(95\%CI) & Quality sore \\
\hline \multirow[t]{2}{*}{ Steevens J(2010) } & Netherlands & case-cohort & 3346 & 129 & $55-69$ & $\mathrm{M}$ and $\mathrm{F}$ & $16.3 \mathrm{Y}$ & Toenail selenium & EAC & $0.76(0.41,1.40)$ & 9 \\
\hline & & & 3346 & 71 & & & & & ESCC & $0.37(0.16,0.86)$ & \\
\hline Cai, L(2006) & China & case-cohort & 633 & 218 & N/A & $\mathrm{M}$ and $\mathrm{F}$ & $10+Y$ & Selenium intake & ESCC & $0.48(0.25,0.89)$ & 9 \\
\hline Wei WQ(2004) & China & cohort & 1103 & 75 & $40-69$ & $\mathrm{M}$ and $\mathrm{F}$ & $15 \mathrm{Y}$ & Serum selenium & ESCC death & $0.83(0.71,0.98)$ & 9 \\
\hline \multirow[t]{2}{*}{ Mark SD(2000) } & China & case-cohort & 1464 & 402 & $40-69$ & $\mathrm{M}$ and $\mathrm{F}$ & $4.5 \mathrm{Y}$ & Serum selenium & Incidence & $0.89(0.83,0.95)$ & 9 \\
\hline & & & & & & & & & morality & $0.90(0.83,0.97)$ & \\
\hline Clark LC(1996) & USA & RCT & P:659, e: 653 & P:6, e: 2 & mean 63 & $\mathrm{M}$ and $\mathrm{F}$ & $6.4 \mathrm{Y}$ & $\begin{array}{l}\text { Selenium supple- } \\
\text { ment }\end{array}$ & $\begin{array}{c}\text { esophageal } \\
\text { cancer }\end{array}$ & $0.33(0.03,1.84)$ & $\begin{array}{c}\text { low risk of } \\
\text { bias }\end{array}$ \\
\hline \multicolumn{12}{|l|}{ Gastric cancer } \\
\hline Steevens J(2010) & Netherlands & case-cohort & 3346 & 114 & $55-69$ & $\mathrm{M}$ and $\mathrm{F}$ & $16.3 \mathrm{Y}$ & Toenail selenium & GCC & $0.52(0.27,1.02)$ & 9 \\
\hline Wei WQ(2004) & China & cohort & 1103 & 36 & $40-69$ & $\mathrm{M}$ and $\mathrm{F}$ & $15 \mathrm{Y}$ & Serum selenium & GCC death & $0.75(0.59,0.95)$ & 9 \\
\hline \multirow[t]{4}{*}{ Mark SD(2000) } & China & case-cohort & 1479 & 87 & $40-69$ & $\mathrm{M}$ and $\mathrm{F}$ & $4.5 \mathrm{Y}$ & Serum selenium & GNC onset & $1.02(0.89,1.18)$ & 9 \\
\hline & & & 1652 & 590 & & & & & GCC onset & $0.83(0.77,0.90)$ & \\
\hline & & & 1149 & 87 & & & & & GNC death & $1.02(0.88,1.20)$ & \\
\hline & & & 1652 & 590 & & & & & GCC death & $0.87(0.79,0.96)$ & \\
\hline Kabuto, M(1994) & Japan & case-control & 428 & 202 & $59-60$ & $\mathrm{M}$ and $\mathrm{F}$ & $13 \mathrm{Y}$ & Serum selenium & $\begin{array}{l}\text { gastric } \\
\text { cancer }\end{array}$ & $1.00(0.50,1.90)$ & 8 \\
\hline $\begin{array}{l}\text { van den Brandt } \\
\text { PA(1993) }\end{array}$ & Netherlands & cohort & 2459 & 92 & $55-69$ & $\mathrm{M}$ and $\mathrm{F}$ & $3.3 \mathrm{Y}$ & Toenail selenium & $\begin{array}{l}\text { gastric } \\
\text { cancer }\end{array}$ & $0.61(0.33,1.11)$ & 9 \\
\hline \multirow[t]{2}{*}{ Knekt P(1990) } & Finland & cohort & N/A & 43 & $15-99$ & Men & $\mathrm{N} / \mathrm{A}$ & Serum selenium & $\begin{array}{l}\text { gastric } \\
\text { cancer }\end{array}$ & $0.24(0.09,0.69)$ & 8 \\
\hline & & & N/A & 30 & & Women & & & & $0.48(0.14,1.66)$ & \\
\hline \multicolumn{12}{|l|}{ Colorectal cancer } \\
\hline \multirow[t]{2}{*}{ Takata Y(2011) } & USA & $\begin{array}{c}\text { nested } \\
\text { case-control }\end{array}$ & 1449 & 648 & $50-79$ & Women & N/A & Serum selenium & colon $\mathrm{Ca}$ & $1.28(0.91,1.79)$ & 9 \\
\hline & & & 950 & 149 & & & & & rectal Ca & $1.25(0.68,2.31)$ & \\
\hline $\begin{array}{l}\text { Connelly-Frost } \\
\mathrm{A}(2009)\end{array}$ & USA & case-control & 1362 & 532 & $40-80$ & $\mathrm{M}$ and $\mathrm{F}$ & $\mathrm{N} / \mathrm{A}$ & Serum selenium & Colon cancer & $0.40(0.20,0.60)$ & 9 \\
\hline Ghadirian $\mathrm{P}(2000)$ & Canada & case-control & 1090 & 402 & $\mathrm{~N} / \mathrm{A}$ & $\mathrm{M}$ and $\mathrm{F}$ & $\mathrm{N} / \mathrm{A}$ & Toenailselenium & $\begin{array}{l}\text { colorectal } \\
\text { cancer }\end{array}$ & $0.42(0.19,0.93)$ & 8 \\
\hline Nelson RL(1995) & USA & case-control & 163 & 25 & $26-87$ & $\mathrm{M}$ and $\mathrm{F}$ & $\mathrm{N} / \mathrm{A}$ & Serum selenium & $\begin{array}{c}\text { colorectal } \\
\text { cancer }\end{array}$ & $1.70(0.50,5.90)$ & 7 \\
\hline Garland M(1995) & USA & $\begin{array}{c}\text { nested } \\
\text { case-control }\end{array}$ & 178 & 89 & $30-55$ & Women & $41 \mathrm{M}$ & Toenailselenium & $\begin{array}{c}\text { colorectal } \\
\text { cancer }\end{array}$ & $2.04(0.88,4.75)$ & 8 \\
\hline \multirow[t]{2}{*}{$\begin{array}{l}\text { van den Brandt } \\
\text { PA(1993) }\end{array}$} & Netherlands & cohort & 2495 & 234 & $55-69$ & $\mathrm{M}$ and $\mathrm{F}$ & $3.3 \mathrm{Y}$ & Toenail & colon $\mathrm{Ca}$ & $0.77(0.49,1.19)$ & 9 \\
\hline & & & 2495 & 113 & & & & selenium & rectal Ca & $1.01(0.55,1.84)$ & \\
\hline \multirow[t]{2}{*}{ Knekt P(1990) } & Finland & cohort & N/A & 29 & $15-99$ & Men & $\mathrm{N} / \mathrm{A}$ & Serum selenium & $\begin{array}{c}\text { colorectal } \\
\text { cancer }\end{array}$ & $1.01(0.18,5.65)$ & 8 \\
\hline & & & & 48 & & Women & & & & $1.10(0.42,2.92)$ & \\
\hline Schober SE(1987) & USA & case-control & 215 & 72 & $<75$ & $\mathrm{M}$ and $\mathrm{F}$ & $\mathrm{N} / \mathrm{A}$ & Serum selenium & colon cancer & $0.71(0.29,1.67)$ & 7 \\
\hline $\begin{array}{l}\text { Lippman } \\
\text { SM(2009) }\end{array}$ & $\begin{array}{l}\text { US, Canada, } \\
\text { Puerto Rico }\end{array}$ & RCT & P:8696,e: 8752 & P:60, e: 63 & $\geq 50$ & men & $5.46 \mathrm{Y}$ & $\begin{array}{l}\text { Selenium supple- } \\
\text { ment }\end{array}$ & $\begin{array}{l}\text { colorectal } \\
\text { cancer }\end{array}$ & $1.09(0.69,1.73)$ & $\begin{array}{l}\text { low risk of } \\
\text { bias }\end{array}$ \\
\hline Clark LC(1996) & USA & RCT & P:659, e: 653 & P:19, e: 8 & mean 63 & $\mathrm{M}$ and $\mathrm{F}$ & $6.4 \mathrm{Y}$ & $\begin{array}{l}\text { Selenium supple- } \\
\text { ment }\end{array}$ & $\begin{array}{c}\text { colorectal } \\
\text { cancer }\end{array}$ & $0.42(0.18,0.95)$ & $\begin{array}{c}\text { low risk of } \\
\text { bias }\end{array}$ \\
\hline \multicolumn{12}{|l|}{ Bladder cancer } \\
\hline Hotaling JM(2011) & USA & cohort & 77050 & 330 & $50-76$ & $\mathrm{M}$ and $\mathrm{F}$ & $6 \mathrm{Y}$ & $\begin{array}{l}\text { Selenium supple- } \\
\text { ment }\end{array}$ & $\begin{array}{l}\text { bladder } \\
\text { cancer }\end{array}$ & $0.97(0.72,1.31)$ & 8 \\
\hline Wallace K(2009) & Germany & case-control & 2048 & 857 & $25-74$ & $\mathrm{M}$ and $\mathrm{F}$ & $\mathrm{N} / \mathrm{A}$ & Toenail selenium & $\begin{array}{l}\text { bladder } \\
\text { cancer }\end{array}$ & $0.90(0.68,1.19)$ & 9 \\
\hline Kellen E(2006) & Belgium & case-control & 540 & 362 & $\geq 50$ & $\mathrm{M}$ and $\mathrm{F}$ & $\mathrm{N} / \mathrm{A}$ & Serumselenium & $\begin{array}{l}\text { bladder } \\
\text { cancer }\end{array}$ & $0.27(0.15,0.47)$ & 9 \\
\hline \multirow[t]{2}{*}{ Michaud DS(2005) } & US & $\begin{array}{c}\text { nested } \\
\text { case-control }\end{array}$ & 446 & 222 & mean 62 & Men & $\mathrm{N} / \mathrm{A}$ & Toenail selenium & $\begin{array}{l}\text { bladder } \\
\text { cancer }\end{array}$ & $1.17(0.66,2.07)$ & 9 \\
\hline & & & 233 & 116 & & Women & & & & $0.36(0.14,0.91)$ & \\
\hline Zeegers MP(2002) & Netherlands & case-cohort & 2890 & 431 & $55-69$ & $\mathrm{M}$ and $\mathrm{F}$ & $6.3 \mathrm{Y}$ & Toenail selenium & $\begin{array}{l}\text { bladder } \\
\text { cancer }\end{array}$ & $0.67(0.47,0.97)$ & 9 \\
\hline Michaud DS(2002) & Finland & $\begin{array}{c}\text { nested } \\
\text { case-control }\end{array}$ & 264 & 132 & $50-69$ & $\mathrm{M}$ and $\mathrm{F}$ & $\mathrm{N} / \mathrm{A}$ & Toenail selenium & $\begin{array}{l}\text { bladder } \\
\text { cancer }\end{array}$ & $0.90(0.45,1.78)$ & 8 \\
\hline $\begin{array}{l}\text { Helzlsouer } \\
\text { KJ(1989) }\end{array}$ & USA & case-control & 95 & 35 & mean 59 & $\mathrm{M}$ and $\mathrm{F}$ & N/A & Serumselenium & $\begin{array}{l}\text { bladder } \\
\text { cancer }\end{array}$ & $0.49(0.16,1.49)$ & 9 \\
\hline Lotan $\mathrm{Y}(2012)$ & $\begin{array}{l}\text { US, Canada, } \\
\text { Puerto Rico }\end{array}$ & RCT & P:8696,e: 8752 & P:35, e: 63 & $\geq 50$ & men & $7.1 \mathrm{Y}$ & $\begin{array}{c}\text { Selenium supple- } \\
\text { ment }\end{array}$ & $\begin{array}{l}\text { bladder } \\
\text { cancer }\end{array}$ & $1.13(0.70,1.84)$ & $\begin{array}{c}\text { low risk of } \\
\text { bias }\end{array}$ \\
\hline \multicolumn{12}{|l|}{ Continued } \\
\hline
\end{tabular}




\begin{tabular}{|c|c|c|c|c|c|c|c|c|c|c|c|}
\hline Study & Country & Design & Subject & Case & age & Gender & Follow-up & $\begin{array}{c}\text { Measurements of } \\
\text { selenium }\end{array}$ & $\begin{array}{l}\text { Type of } \\
\text { cancer }\end{array}$ & $\mathrm{OR}(95 \% \mathrm{CI})$ & Quality sore \\
\hline Clark LC(1996) & USA & RCT & P:659, e: 653 & P:6, e: 8 & mean 63 & $\mathrm{M}$ and $\mathrm{F}$ & $6.4 \mathrm{Y}$ & $\begin{array}{c}\text { Selenium supple- } \\
\text { ment }\end{array}$ & $\begin{array}{l}\text { bladder } \\
\text { cancer }\end{array}$ & $1.27(0.44,3.67)$ & $\begin{array}{c}\text { low risk of } \\
\text { bias }\end{array}$ \\
\hline \multicolumn{12}{|l|}{ Prostate cancer } \\
\hline $\begin{array}{l}\text { Geybels, M } \\
\text { S(2013) }\end{array}$ & Netherlands & Case-cohort & 2074 & 898 & $55-69$ & Men & $7 \mathrm{Y}$ & Toenail selenium & $\begin{array}{l}\text { prostate } \\
\text { cancer }\end{array}$ & $0.37(0.27,0.51)$ & 9 \\
\hline $\begin{array}{l}\text { Grundmark, } \\
\mathrm{B}(2011)\end{array}$ & Sweden & cohort & 2045 & 208 & 50 & Men & $34 \mathrm{Y}$ & Serum selenium & $\begin{array}{l}\text { Prostate } \\
\text { cancer }\end{array}$ & $0.83(0.60,1.16)$ & 9 \\
\hline $\begin{array}{l}\text { Steinbrecher, } \\
\mathrm{A}(2010)\end{array}$ & European & $\begin{array}{c}\text { Nested } \\
\text { case-control }\end{array}$ & 734 & 244 & $40-64$ & Men & N/A & Serum selenium & $\begin{array}{l}\text { Prostate } \\
\text { cancer }\end{array}$ & $0.78(0.49,1.22)$ & 9 \\
\hline Gill, J K(2009) & USA & $\begin{array}{c}\text { Nested } \\
\text { case-control }\end{array}$ & 1403 & 467 & $45-75$ & Men & N/A & Serum selenium & $\begin{array}{l}\text { Prostate } \\
\text { cancer }\end{array}$ & $0.82(0.59,1.14)$ & 9 \\
\hline Allen, N E(2008) & Europe & $\begin{array}{c}\text { Nested } \\
\text { case-control }\end{array}$ & 2018 & 959 & $43-76$ & Men & $2.6-9.2 \mathrm{Y}$ & Serum selenium & $\begin{array}{l}\text { Prostate } \\
\text { cancer }\end{array}$ & $0.96(0.70,1.31)$ & 9 \\
\hline $\begin{array}{l}\text { Pourmand, } \\
\text { G(2008) }\end{array}$ & Iran & case-control & 130 & 62 & $40-90$ & Men & N/A & Serum selenium & $\begin{array}{l}\text { Prostate } \\
\text { cancer }\end{array}$ & $0.16(0.06,0.47)$ & 8 \\
\hline Peters, U(2008) & USA & cohort & 35242 & 693 & $50-76$ & men & N/A & $\begin{array}{l}\text { selenium supple- } \\
\text { ment }\end{array}$ & $\begin{array}{l}\text { Prostate } \\
\text { cancer }\end{array}$ & $1.00(0.68,1.50)$ & 9 \\
\hline Peters, U(2007) & USA & $\begin{array}{c}\text { Nested } \\
\text { case-control }\end{array}$ & 1603 & 724 & $55-74$ & men & $8 \mathrm{Y}$ & Serum selenium & $\begin{array}{l}\text { Prostate } \\
\text { cancer }\end{array}$ & $0.84(0.62,1.14)$ & 9 \\
\hline Lipsky, K(2004) & Austria & case-control & 150 & 70 & $48-95$ & men & N/A & Toenail selenium & $\begin{array}{l}\text { Prostate } \\
\text { cancer }\end{array}$ & $0.74(0.22,2.71)$ & 8 \\
\hline Li H(2004) & USA & $\begin{array}{c}\text { Nested } \\
\text { case-control }\end{array}$ & 1143 & 586 & $40-84$ & men & $13 \mathrm{Y}$ & Serum selenium & $\begin{array}{l}\text { Prostate } \\
\text { cancer }\end{array}$ & $0.78(0.54,1.13)$ & 9 \\
\hline Allen, N E(2004) & Britain & case-control & 600 & 300 & $44-77$ & men & N/A & Toenail selenium & $\begin{array}{l}\text { Prostate } \\
\text { cancer }\end{array}$ & $1.24(0.73,2.10)$ & 9 \\
\hline $\begin{array}{l}\text { van den Brandt, } P \\
\mathrm{~A}(2003)\end{array}$ & Netherlands & Cohort & 1751 & 540 & $55-69$ & men & $6.3 \mathrm{Y}$ & Toenail selenium & $\begin{array}{l}\text { Prostate } \\
\text { cancer }\end{array}$ & $0.69(0.48,0.99)$ & 9 \\
\hline $\begin{array}{l}\text { Goodman, G } \\
\text { E(2001) }\end{array}$ & USA & case-control & 691 & 235 & $45-74$ & men & N/A & Serum selenium & $\begin{array}{l}\text { Prostate } \\
\text { cancer }\end{array}$ & $1.02(0.65,1.60)$ & 9 \\
\hline Brooks, J D(2001) & USA & case-control & 148 & 52 & 68 & men & N/A & Serum selenium & $\begin{array}{l}\text { Prostate } \\
\text { cancer }\end{array}$ & $0.24(0.07,0.77)$ & 9 \\
\hline Ghadirian, $\mathrm{P}(2000)$ & Canada & case-control & 165 & 83 & $35-84$ & men & N/A & Toenail selenium & $\begin{array}{l}\text { Prostate } \\
\text { cancer }\end{array}$ & $1.14(0.46,2.83)$ & 8 \\
\hline $\begin{array}{l}\text { Helzlsouer, K } \\
\text { J(2000) }\end{array}$ & USA & $\begin{array}{c}\text { Nested } \\
\text { case-control }\end{array}$ & 350 & 117 & 70 & men & N/A & Serum selenium & $\begin{array}{c}\text { Prostate } \\
\text { cancer }\end{array}$ & $0.38(0.17,0.85)$ & 8 \\
\hline $\begin{array}{l}\text { Nomura, A } \\
\mathrm{M}(2000)\end{array}$ & USA & $\begin{array}{c}\text { Nested } \\
\text { case-control }\end{array}$ & 498 & 249 & $44-85$ & men & N/A & Serum selenium & $\begin{array}{l}\text { Prostate } \\
\text { cancer }\end{array}$ & $0.50(0.30,0.90)$ & 9 \\
\hline $\begin{array}{l}\text { Hartman, T } \\
\text { J(1998) }\end{array}$ & USA & cohort & 29460 & 317 & 61 & men & $9 \mathrm{Y}$ & Serum selenium & $\begin{array}{l}\text { Prostate } \\
\text { cancer }\end{array}$ & $1.32(0.70,2.47)$ & 9 \\
\hline $\begin{array}{l}\text { Yoshizawa, } \\
\text { K(1998) }\end{array}$ & USA & $\begin{array}{c}\text { Nested } \\
\text { case-control }\end{array}$ & 362 & 181 & $40-75$ & men & $7 \mathrm{Y}$ & Toenail selenium & $\begin{array}{l}\text { Prostate } \\
\text { cancer }\end{array}$ & $0.35(0.16,0.78)$ & 9 \\
\hline Hardell, L(1995) & Sweden & case-control & 245 & 124 & $44-87$ & men & N/A & Serum selenium & $\begin{array}{l}\text { Prostate } \\
\text { cancer }\end{array}$ & $0.30(0.10,0.70)$ & 7 \\
\hline \multirow[t]{2}{*}{ West, D W(1991) } & USA & case-control & 564 & 179 & $45-67$ & men & N/A & selenium & $\begin{array}{l}\text { Prostate } \\
\text { cancer }\end{array}$ & $0.80(0.50,1.40)$ & 9 \\
\hline & & & 473 & 179 & $68-74$ & & & supplement & & $1.60(1.00,2.80)$ & \\
\hline Knekt, P(1990) & Finland & cohort & N/A & 46 & $15-99$ & men & N/A & Serum selenium & $\begin{array}{l}\text { Prostate } \\
\text { cancer }\end{array}$ & $1.00(0.42,2.4)$ & 8 \\
\hline \multirow[t]{2}{*}{$\begin{array}{l}\text { Lippman } \\
\text { SM(2009) }\end{array}$} & $\begin{array}{l}\text { US, Canada, } \\
\text { Puerto Rico }\end{array}$ & RCT & P:8696,e: 8752 & P:416 & $\geq 50$ & men & $5.46 \mathrm{Y}$ & $\begin{array}{l}\text { Selenium supple- } \\
\text { ment }\end{array}$ & $\begin{array}{l}\text { Prostate } \\
\text { cancer }\end{array}$ & $1.04(0.83,1.30)$ & $\begin{array}{c}\text { low risk of } \\
\text { bias }\end{array}$ \\
\hline & & & & e:432 & & & & & & & \\
\hline \multirow[t]{2}{*}{$\begin{array}{l}\text { Duffield-Lillico, A } \\
\text { J(2003) }\end{array}$} & USA & RCT & P:470; & P: 42; & 65 & men & $7.5 \mathrm{Y}$ & selenium & $\begin{array}{l}\text { Prostate } \\
\text { cancer }\end{array}$ & $0.48(0.28,0.80)$ & $\begin{array}{c}\text { low risk of } \\
\text { bias }\end{array}$ \\
\hline & & & E:457 & E: 22 & & & & supplement & & & \\
\hline Clark LC(1996) & USA & RCT & P:659, e: 653 & P:35, e: 13 & mean 63 & men & $6.4 \mathrm{Y}$ & $\begin{array}{c}\text { Selenium supple- } \\
\text { ment }\end{array}$ & $\begin{array}{l}\text { Prostate } \\
\text { cancer }\end{array}$ & $0.35(0.18,0.65)$ & $\begin{array}{c}\text { low risk of } \\
\text { bias }\end{array}$ \\
\hline \multicolumn{12}{|l|}{ Skin cancer } \\
\hline Garland M(1995) & USA & $\begin{array}{c}\text { nested } \\
\text { case-control }\end{array}$ & $30-55$ & 126 & 63 & women & $41 \mathrm{M}$ & Toenail selenium & melanoma & $1.66(0.71,3.85)$ & 8 \\
\hline \multirow[t]{2}{*}{ Knekt P(1990) } & USA & cohort & $15-99$ & $\mathrm{~N} / \mathrm{A}$ & 54 & Men & N/A & Serum selenium & $\begin{array}{c}\text { basal cell } \\
\text { carcinoma }\end{array}$ & $0.86(0.35,2.12)$ & 8 \\
\hline & & & & & 52 & Women & & & & $1.54(0.64,3.75)$ & \\
\hline Reid ME(2008) & USA & RCT & P:210, e: 213 & P:108e: 98 & mean 63 & $\mathrm{M}$ and $\mathrm{F}$ & $6.4 \mathrm{Y}$ & $\begin{array}{l}\text { Selenium supple- } \\
\text { ment }\end{array}$ & $\begin{array}{l}\text { non-mela- } \\
\text { noma skin } \\
\text { cancer }\end{array}$ & $0.91(0.69,1.20)$ & $\begin{array}{c}\text { low risk of } \\
\text { bias }\end{array}$ \\
\hline
\end{tabular}




\begin{tabular}{|c|c|c|c|c|c|c|c|c|c|c|c|}
\hline Study & Country & Design & Subject & Case & age & Gender & Follow-up & $\begin{array}{l}\text { Measurements of } \\
\text { selenium }\end{array}$ & $\begin{array}{l}\text { Type of } \\
\text { cancer }\end{array}$ & OR(95\%CI) & Quality sore \\
\hline Clark LC(1996) & USA & RCT & P:659, e: 653 & P:190e:218 & mean 63 & $\mathrm{M}$ and $\mathrm{F}$ & $6.4 \mathrm{Y}$ & $\begin{array}{l}\text { Selenium supple- } \\
\text { ment }\end{array}$ & $\begin{array}{l}\text { squamous } \\
\text { cell carcino- } \\
\text { ma basal cell } \\
\text { carcinoma }\end{array}$ & $1.14(0.93,1.39)$ & $\begin{array}{l}\text { low risk of } \\
\text { bias }\end{array}$ \\
\hline & & & & P:350e:377 & & & & & & $1.10(0.95,1.28)$ & \\
\hline \multicolumn{12}{|l|}{ Other cancer } \\
\hline Knekt P(1990) & USA & cohort & $15-99$ & N/A & 26 & Men & N/A & Serum selenium & $\begin{array}{l}\text { Urinary tract } \\
\text { cancer }\end{array}$ & $0.34(0.06,2.06)$ & 8 \\
\hline Knekt P(1990) & USA & cohort & $15-99$ & N/A & 22 & Women & N/A & Serum selenium & $\begin{array}{c}\text { Pancreas } \\
\text { cancer }\end{array}$ & $0.86(0.21,3.52)$ & 8 \\
\hline Clark LC(1996) & USA & $\mathrm{RCT}$ & P:659, e: 653 & P:5, e: 8 & mean 63 & $\mathrm{M}$ and $\mathrm{F}$ & $6.4 \mathrm{Y}$ & $\begin{array}{l}\text { Selenium supple- } \\
\text { ment }\end{array}$ & $\begin{array}{l}\text { leukemia/ } \\
\text { lymphomas }\end{array}$ & $1.50(0.49,4.60)$ & $\begin{array}{l}\text { low risk of } \\
\text { bias }\end{array}$ \\
\hline Garland M(1995) & USA & $\begin{array}{c}\text { nested- } \\
\text { case-control }\end{array}$ & 182 & 91 & $30-55$ & women & $41 \mathrm{M}$ & Toenail selenium & $\begin{array}{l}\text { Uterine } \\
\text { cancer }\end{array}$ & $1.38(0.62,3.08)$ & 8 \\
\hline Garland M(1995) & USA & $\begin{array}{c}\text { nested } \\
\text { case-control }\end{array}$ & 182 & 91 & $30-55$ & women & $41 \mathrm{M}$ & Toenail selenium & $\begin{array}{l}\text { Ovarian } \\
\text { cancer }\end{array}$ & $1.22(0.44,3.38)$ & 8 \\
\hline
\end{tabular}

Table 1. Characteristics of studies included in meta-analysis of studies on selenium and cancer. Abbreviation: M and F: Male and Female; p: placebo; e: exposure; RCT: randomized controlled trials; N/A: not available; EAC: esophageal adenocarcinoma; ESCC: esophageal squamous cell carcinoma; GCC: gastric cardia cancer; GNC: gastric noncardia cancer; M: months; Y: years.

presented, and used midpoint when selenium exposure ranges were presented. When highest or lowest categories of selenium exposure were unbounded, we assumed the category width to be the same as the adjacent one. Number of subjects or person-time and number of cases for at least three categories of selenium exposure were also needed in dose-response analyses. We used restricted cubic splines method ${ }^{16}$ described by Orsini, $\mathrm{N}$ et al. to test the possible nonlinear relations, applying three fixed knots at 10\%,50\% and $90 \%$ of selenium exposure level. The dose-response analyses were produced when there were more than 2 studies with relevant data.

Pooled ORs of selenium exposure with $95 \%$ confidence intervals (CI) for cancer risk were conducted by using fixed or random effects model. Heterogeneity was examined by using $\mathrm{Q}^{17}$ and $I^{2}{ }^{18}$ index. When Q-test and $\mathrm{I}^{2}$ statistics does not presented a notable heterogeneity $\left(P>0.05\right.$ and $\left.I^{2} \leq 50 \%\right)$, we used a fixed-effects analysis described by Mantel-Haenszel ${ }^{19}$. Otherwise, a random-effects analysis would be conducted described by DerSimonian and Laird method ${ }^{20}$. Publication bias was tested by Begger's test and a weighted Egger test ${ }^{21,22}$. We also conducted sensitivity analyses by omitting one study at a time to present relative influence of each study on pooled ORs. Statistical calculations and figures were produced with software STATA version 12.0 (StataCorp LP, College Station, TX, USA).

\section{Results}

Characteristics of the study. The meta-analysis included 69 studies ( 26 case-control studies, 14 cohort studies, 19 nested case-control studies, 5 case-cohort studies, 5 randomized controlled trials) reporting 114 independent estimates (as shown in table 1) from Asia (4 studies from China, 2 from Japan, and 1 from Malaysia, Iran, and India, respectively), Europe ( 8 from Netherlands, 5 studies from Sweden, 5 from Finland, 3 from Poland, 2 from Belgium, 1 from Northern Ireland, Britain, Germany and France, respectively, and 3 studies from European countries) and America (27 studies from the United States, 2 from Canada and 1 from Austria). There were more than 364742 participants with 26138 cancer events. 5 studies used all types of cancer as outcome, 14 studies used breast cancer as outcome, 13 studies used lung cancer as outcome, 5 studies used esophageal cancer as outcome, 6 studies used gastric cancer as outcome, 10 studies used colorectal cancer as outcome, 9 studies used bladder cancer as outcome, 25 studies used prostate cancer as outcome, 4 studies used skin cancer as outcome, 1 study regarded urinary tract cancer, pancreas cancer, leukemia/lymphoma, uterine and ovarian cancer as outcome respectively. 11 studies $^{23-33}$ mentioned above reported more than one cancer as an outcome, and several studies reported more than one estimate (as shown in table 1). 56 studies assessed biochemical selenium status: 37 used plasma/serum specimens and 19 used toenail specimens as exposure. 11 studies investigated selenium supplement or intake as exposure, using interviews or validated food frequency questionnaires. One study ${ }^{34}$ used breast tissue selenium as exposure, and the last one ${ }^{35}$ reported selenium intake, plasma selenium and toenail selenium as exposure respectively.

Selenium exposure and all cancer. The relation between selenium exposure and all cancer risk, represented 114 independent estimates from 69 studies (as shown in Table 1). Meta-regression was done to detect the possible influencing factors, and we found that exposure mode (plasma/serum selenium, toenail selenium or selenium supplement), area (Asia, Europe and America) and design (case-control, cohort or RCT) were not influencing factors (exposure mode: $P=0.388$; area: $P=0.523$; design: $P=0.715$ ). Therefore, we took the 114 estimates into meta-analysis. The result of the pooled analysis showed that high selenium exposure had a protective efficacy on cancer at the highest compared with the lowest category (pooled $\mathrm{OR}=0.78$; 95\%CI: $0.73-0.83$ ), with obvious heterogeneity $\left(\mathrm{Q}=423.52 ; P=0.000 ; \mathrm{I}^{2} \%=73.3\right)$ and publication bias (Begger's test $z_{c}=2.55, P=0.011$; Egger's test $t=-2.61, P=0.010$ ). Sensitivity analysis showed that the result was robust (as shown in Supplementary Table S1). The heterogeneity was due to a large amount of included estimates and different types of cancer. 


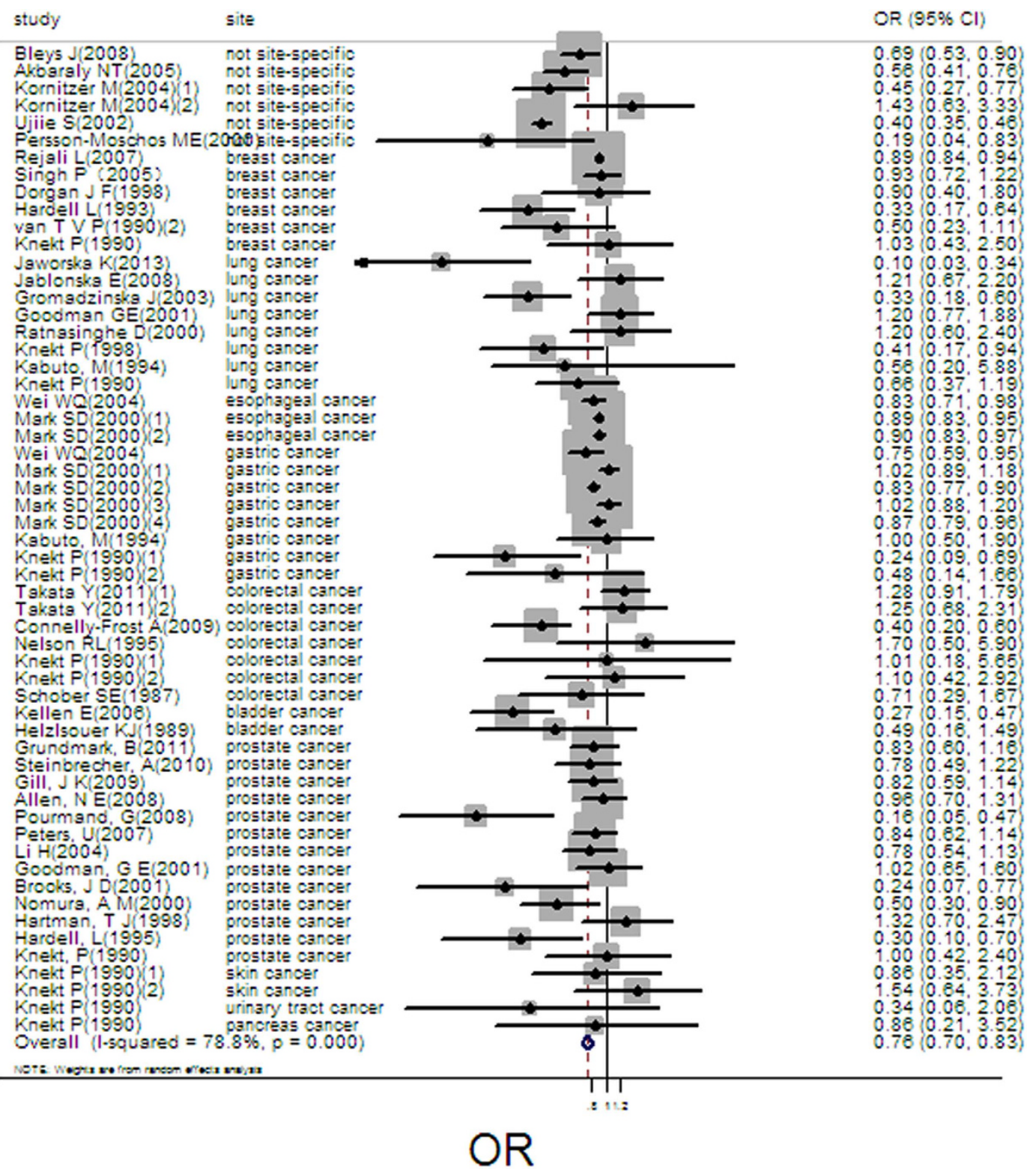

Figure 2. Forest plot of meta-analysis on serum/plasma selenium and cancer risk.

The pooled result from 58 independent estimates showed that high serum/plasma selenium had a effect on cancer prevention at the highest compared with the lowest category (pooled OR $=0.75,95 \% \mathrm{CI}: 0.69-0.82$, Fig. 2), with obvious heterogeneity $\left(\mathrm{Q}=268.57 ; P=0.000 ; \mathrm{I}^{2} \%=78.8\right)$ and publication bias (Begger's test $z_{c}=2.54$, $P=0.025$; Egger's test $\mathrm{t}=-2.43, P=0.018$ ). But the funnel plot was symmetry (supplementary Fig. S1). The heterogeneity could be due to a large amount of included estimates and publication bias. 17 groups of data were incorporated into dose-response analysis. The pooled OR was 0.95 (95\%CI: 0.94-0.98) with $10 \mathrm{ug} / \mathrm{L}$ increase of plasma/serum selenium. Otherwise, we found obvious downward trends in the plots between plasma/serum selenium and total cancer risk in nonlinear dose-response analysis $(P=0.67$ for non-linearity, Fig. 3$)$.

There were 32 independent estimates describing the relation between toenail selenium and cancer risk. The result showed that high toenail selenium decreased cancer risk (pooled $\mathrm{OR}=0.74,95 \% \mathrm{CI}$ : 0.62-0.87, as shown in Fig. 4), with obvious heterogeneity $\left(\mathrm{Q}=70.95, P=0.000 ; I^{2} \%=56.3\right)$. There was no publication bias (Begger's test $z_{c}=0.05 ; P=0.961$; Egger's test $t=0.52, P=0.605$ ), and the funnel plot did not show asymmetry (Fig. S2). 15 groups of data were incorporated into dose-response analysis. The pooled OR was 0.94 (95\%CI: 0.92-0.97) with per $0.1 \mathrm{ug} / \mathrm{g}$ increase of toenail selenium. An downward trends was found in the plots of nonlinear dose-response analysis between toenail selenium and cancer risk $(P=0.500$ for non-linearity, Fig. 5$)$.

There were 23 independent estimates describing the relation between selenium supplement and cancer risk. The result showed that selenium supplement was not associated with cancer risk (pooled OR $=0.91$; 95\%CI: $0.80-1.03$, Fig. 6), with obvious heterogeneity $\left(\mathrm{Q}=49.35, P=0.001 ; I^{2} \%=55.4\right)$. There was no publication bias (Begger's test $z_{c}=1.98 ; P=0.05$; Egger's test $t=0.06, P=0.21$ ), and the funnel plot did not show 


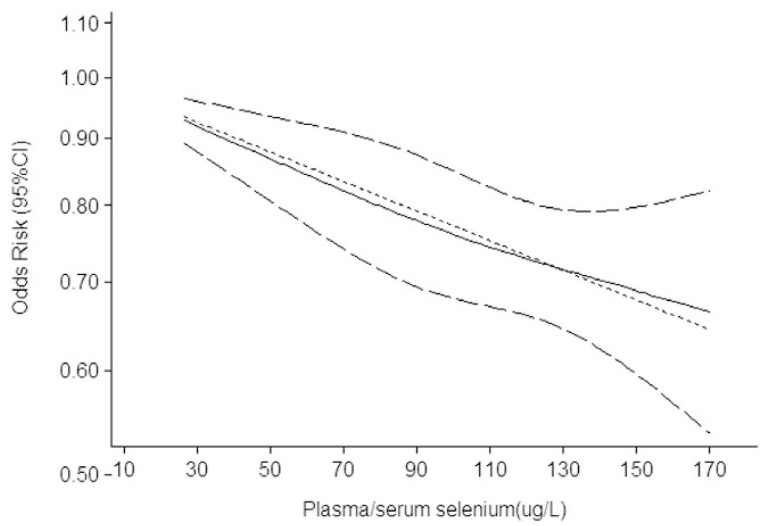

Figure 3. Summary nonlinear dose-response curves: plasma/serum selenium and cancer risk.

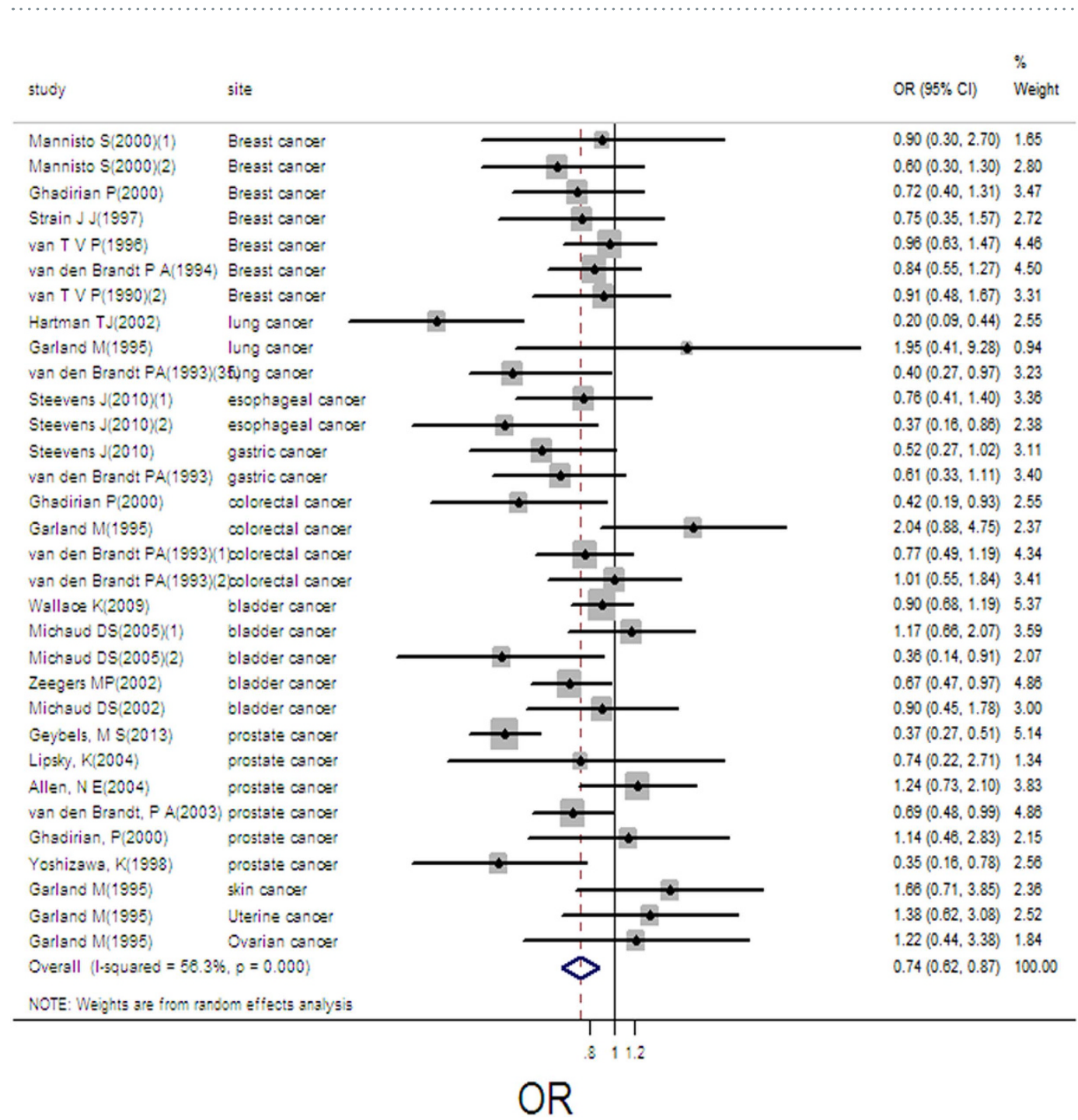

Figure 4. Forest plot of meta-analysis on toenail selenium and cancer risk.

asymmetry (Fig. S3). However, we just extracted two relevant data for selenium supplement and all cancer risk, the linear or nonlinear dose-response analysis was not conducted.

Selenium exposure and breast cancer. 18 estimates from 14 studies were incorporated in the pooled analysis. We found that exposure mode, area and design were not influencing factor (exposure mode: $P=0.417$; 


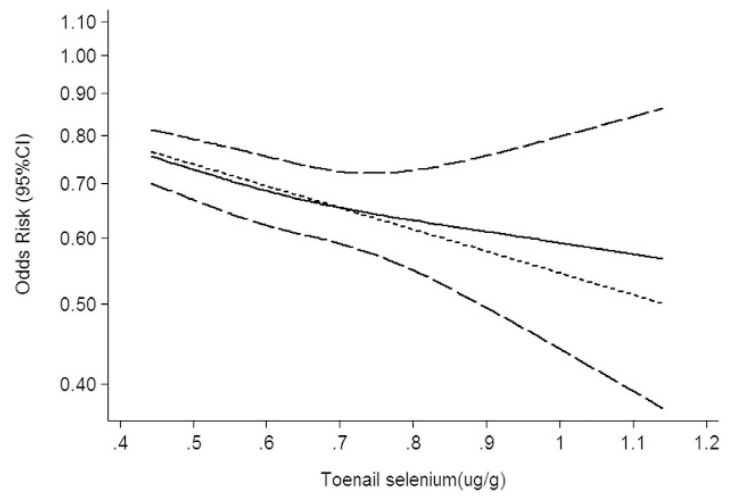

Figure 5. Summary nonlinear dose-response curves: toenail selenium and cancer risk.

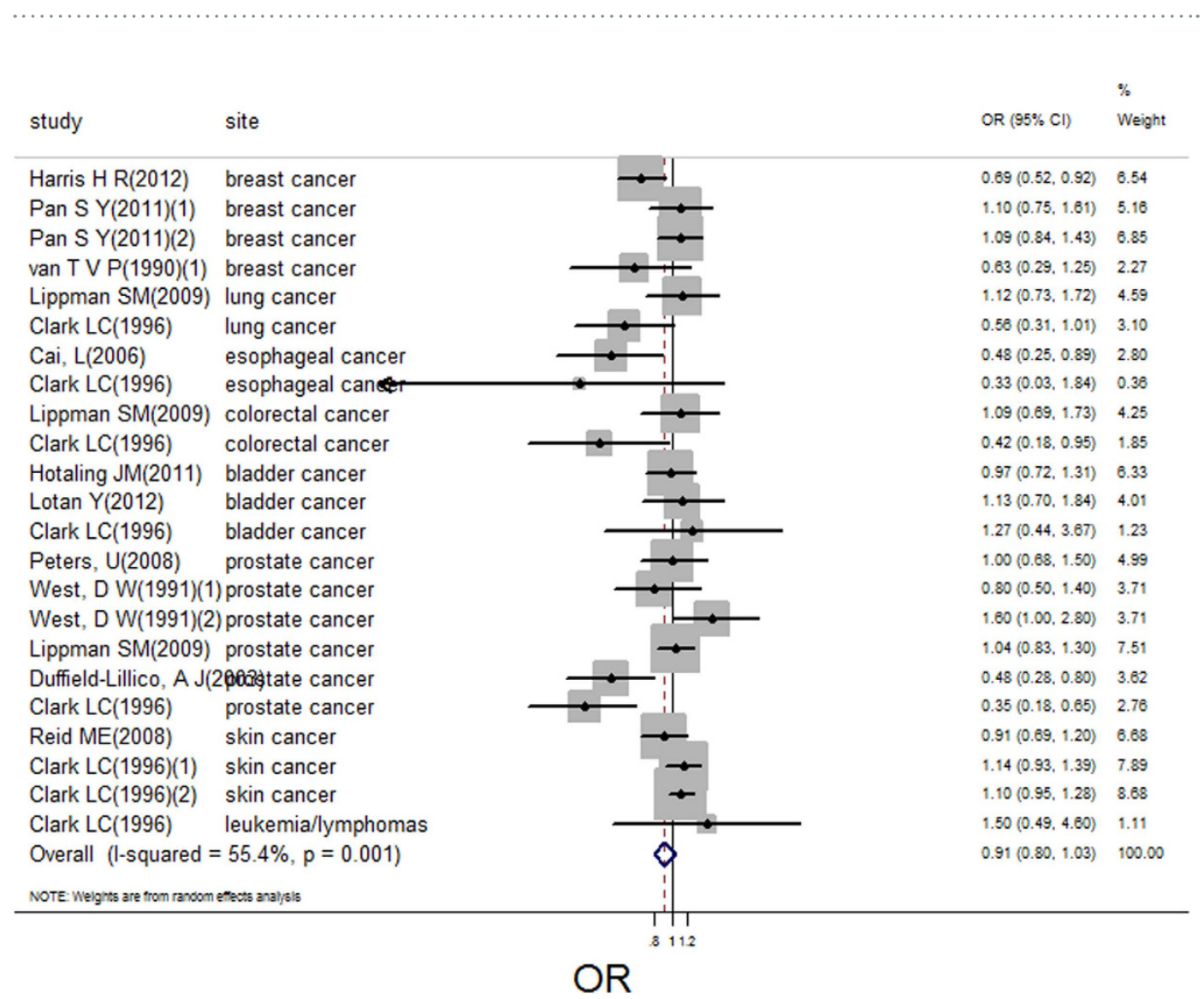

Figure 6. Forest plot of meta-analysis on selenium supplement and cancer risk.

area: $P=0.705$; design: $P=0.095)$ after Meta-regression. The pooled result showed that high selenium exposure decreased risk of breast cancer (pooled $\mathrm{OR}=0.88$; 95\%CI: 0.84-0.93, Fig. 7), with no heterogeneity $(\mathrm{Q}=20.83$, $P=0.234 ; I^{2} \%=18.4$ ) and publication bias (Begger's test $z_{c}=1.74 ; P=0.081$; Egger's test $t=-1.21, P=0.245$ ). Sensitivity analysis showed the result was robust (as shown in Supplemental Table S1). We lacked sufficient data to conduct the linear or nonlinear dose-response analysis.

Selenium exposure and lung cancer. 13 estimates from 13 studies were incorporated into the pooled analysis. We found that exposure mode, area and design were not influencing factor(exposure mode: $P=0.706$; area: $P=0.581$; design: $P=0.705)$. Therefore, we took the 13 estimates into meta-analysis. The result showed that high selenium exposure presented a protective effect on lung cancer (pooled OR $=0.60,95 \%$ CI: $0.41-0.88$, Fig. 8), with moderate heterogeneity $\left(\mathrm{Q}=52.34, P=0.000 ; I^{2} \%=77.1\right)$, but without publication bias (Begger's test $z_{c}=1.16 ; P=0.246$; Egger's test $t=-0.79, P=0.448$ ). Sensitivity analysis showed the result was robust (Supplemental Table S1). 5 groups of data were incorporated into dose-response analysis between plasma/serum selenium and lung cancer risk. The result of linear dose-response analysis presented that plasma/serum selenium 


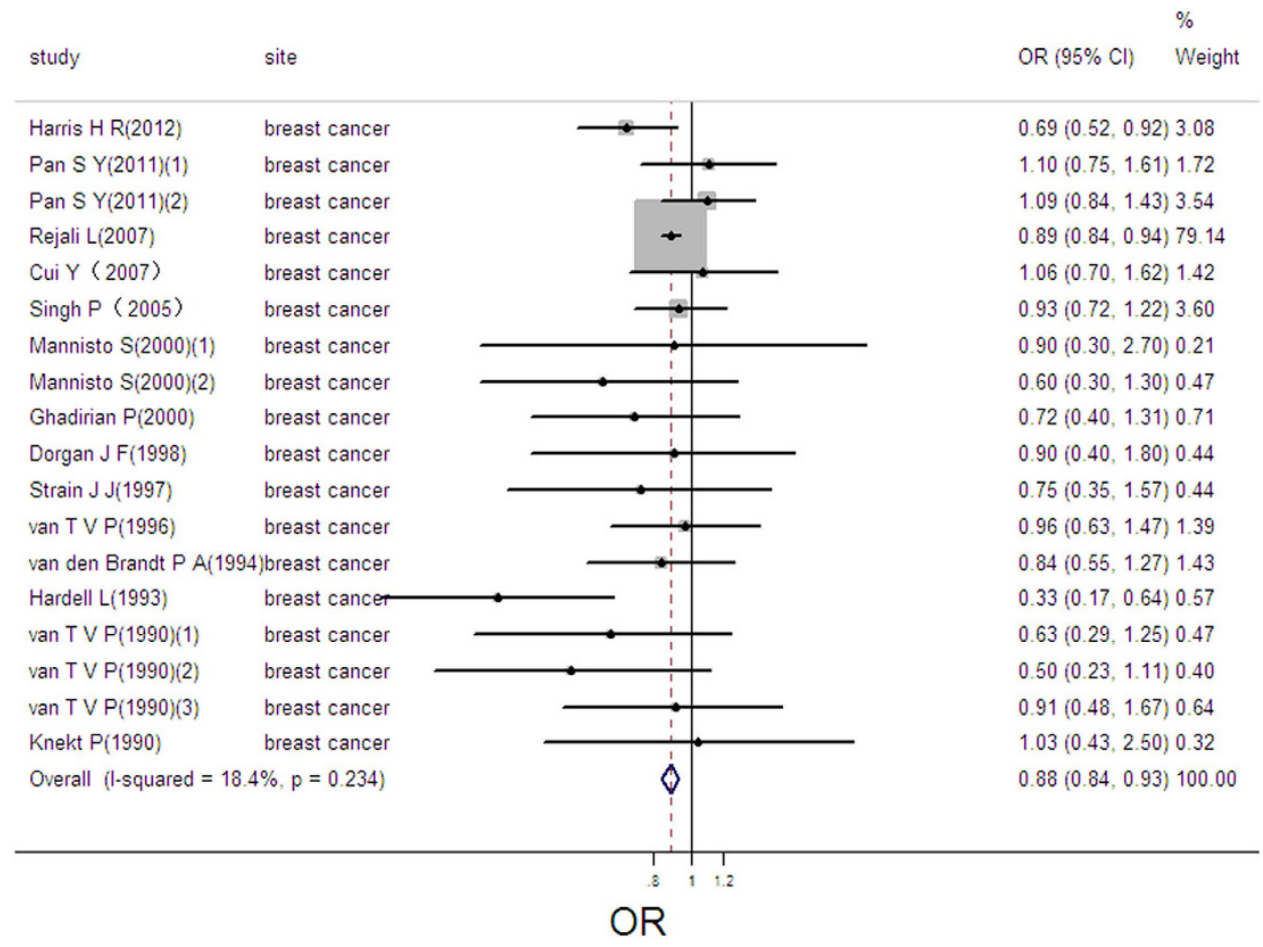

Figure 7. Forest plot of meta-analysis on selenium and breast cancer.

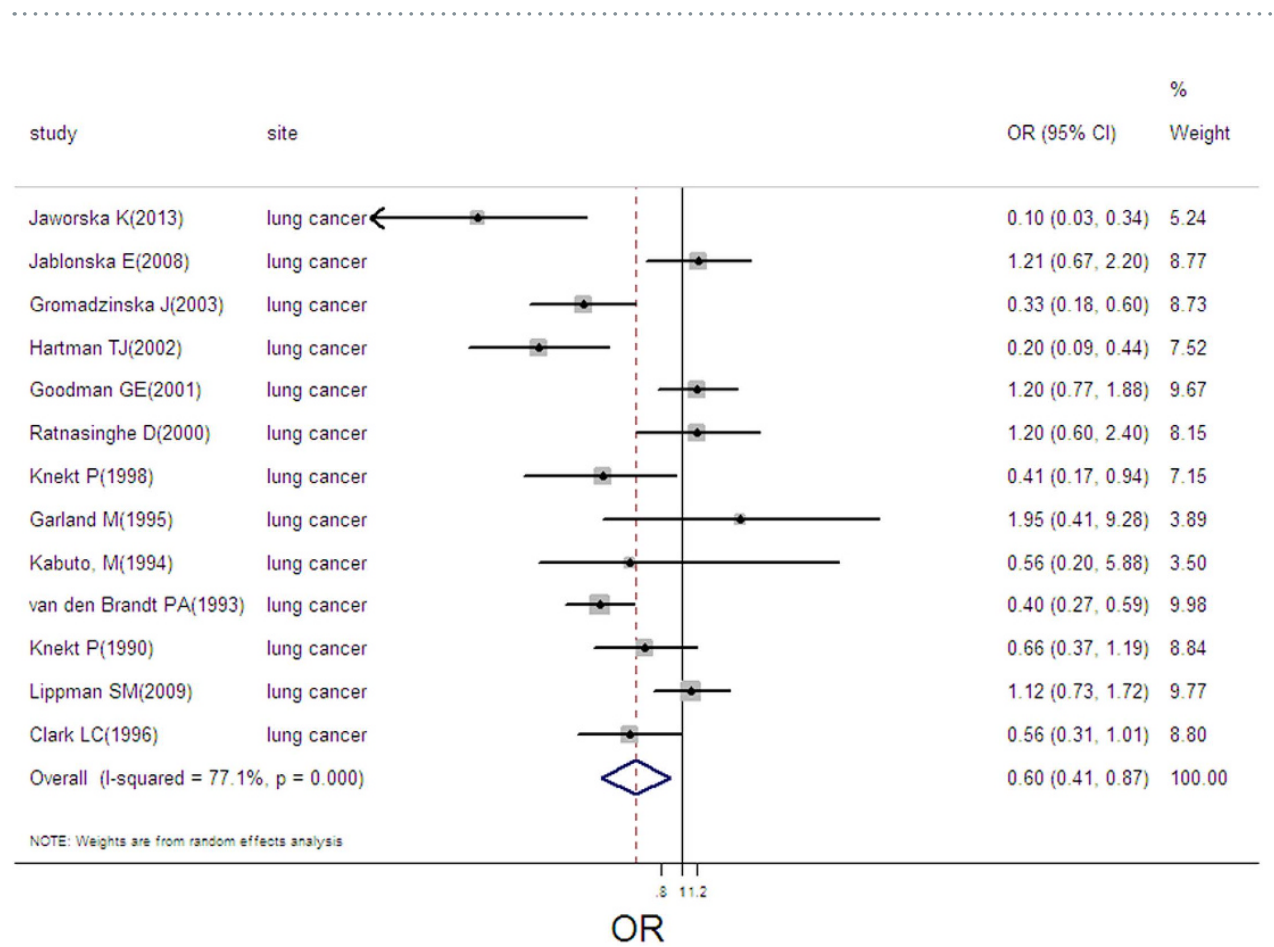

Figure 8. Forest plot of meta-analysis on selenium and lung cancer.

was not associated with cancer risk per $10 \mathrm{ug} / \mathrm{L}$ increases of plasma/serum selenium (pooled OR, 0.92; 95\%CI: $0.83-1.01, P=0.0001$ ). Otherwise, we did not find a threshold effect in the plot between plasma/serum selenium and lung cancer risk in nonlinear dose-response analysis $(P=0.182$ for non-linearity; Fig. S4).

Selenium exposure and esophageal cancer. 7 estimates from 5 studies were incorporated into the pooled analysis. The pooled OR was 0.88 (95\%CI: $0.84-0.93$, Fig. 9$)$ with no heterogeneity $(\mathrm{Q}=9.60, P=0.142$; $I^{2} \%=37.5$ ) and publication bias (Begger's test $z_{c}=1.80 ; P=0.072$; Egger's test $t=-4.57, P=0.006$ ). Sensitivity 


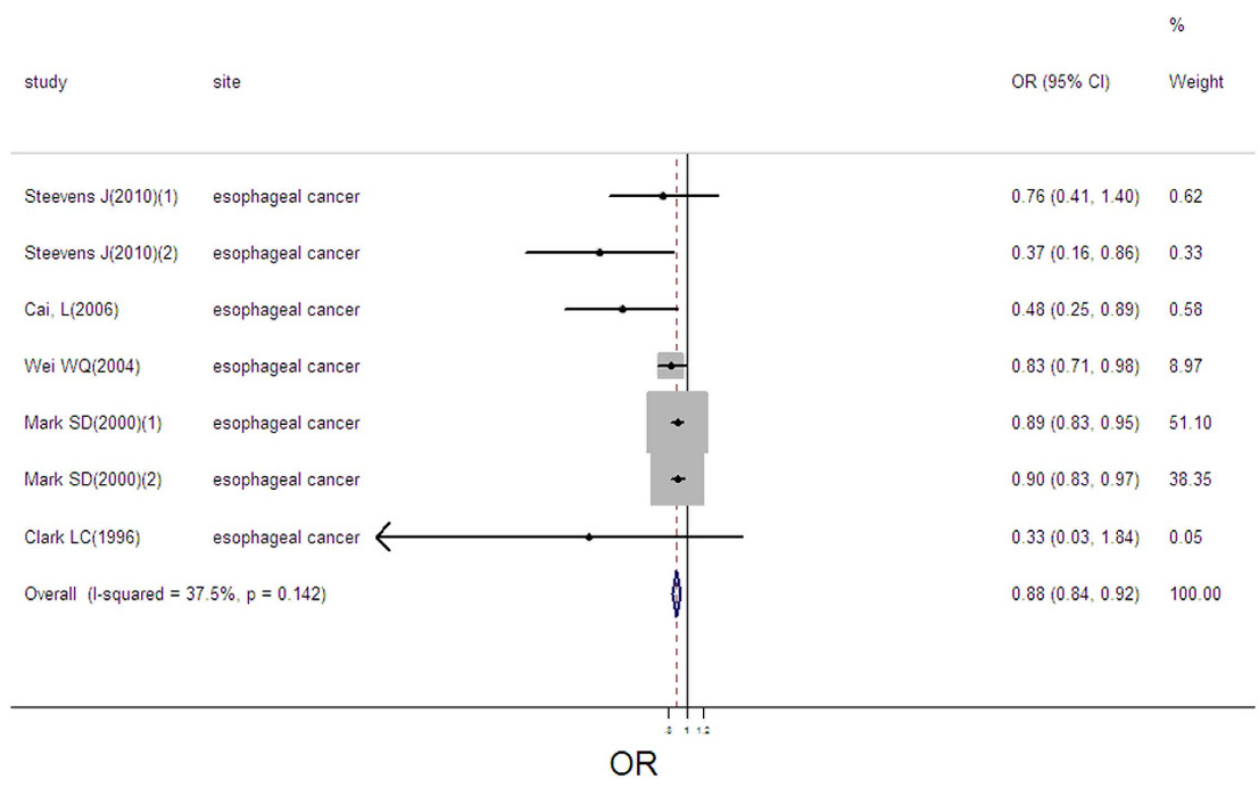

Figure 9. Forest plot of meta-analysis on selenium and esophageal cancer.

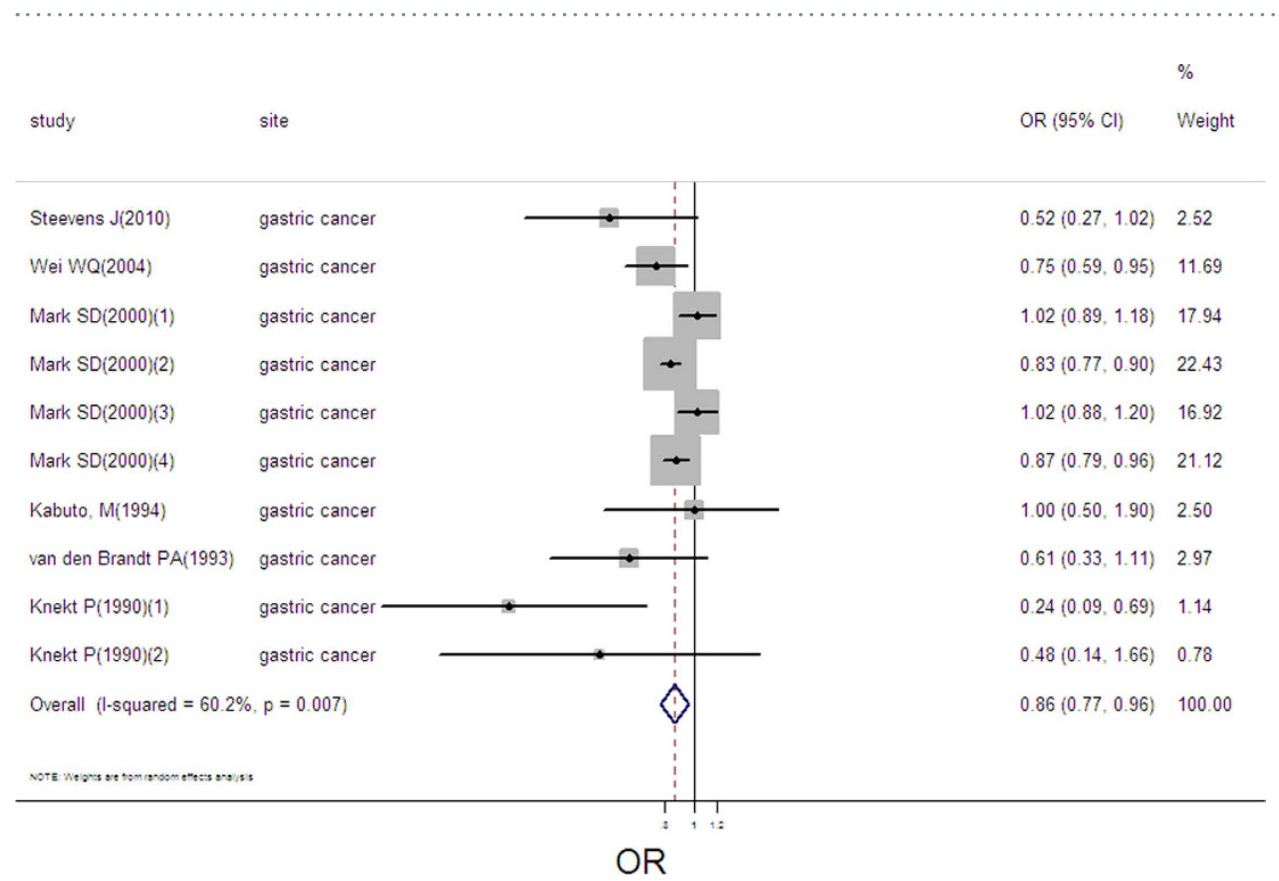

Figure 10. Forest plot of meta-analysis on selenium and gastric cancer.

analysis showed that the result was robust (Supplemental Table S1). We lacked sufficient data to conduct the linear or nonlinear dose-response analysis.

Selenium exposure and gastric cancer. 10 estimates from 6 studies were incorporated into the pooled analysis. We found that exposure mode, area and design were not influencing factor (exposure mode: $P=0.288$; area: $P=0.077$; design: $P=0.769)$. Therefore, we took the 10 estimates into meta-analysis. The pooled $\mathrm{OR}$ was 0.86 (95\%CI: $0.77-0.96$, as shown in Fig. 10$)$ with moderate heterogeneity $\left(\mathrm{Q}=22.63, P=0.007 ; I^{2} \%=60.2\right)$. There was no publication bias (Begger's test $z_{c}=0.54 ; P=0.592$; Egger's test $t=-1.29, P=0.235$ ). Sensitivity analysis showed that the result was robust (as shown in Supplemental Table S1). We lacked sufficient data to conduct the linear or nonlinear dose-response analysis.

Selenium exposure and colorectal cancer. 13 estimates from 10 studies were incorporated into the pooled analysis. We found that exposure mode, area and design were not influencing factor (exposure mode: $P=0.671$; area: $P=0.871$; design: $P=0.963$ ). Therefore, we took the 13 estimates into meta-analysis. The result 


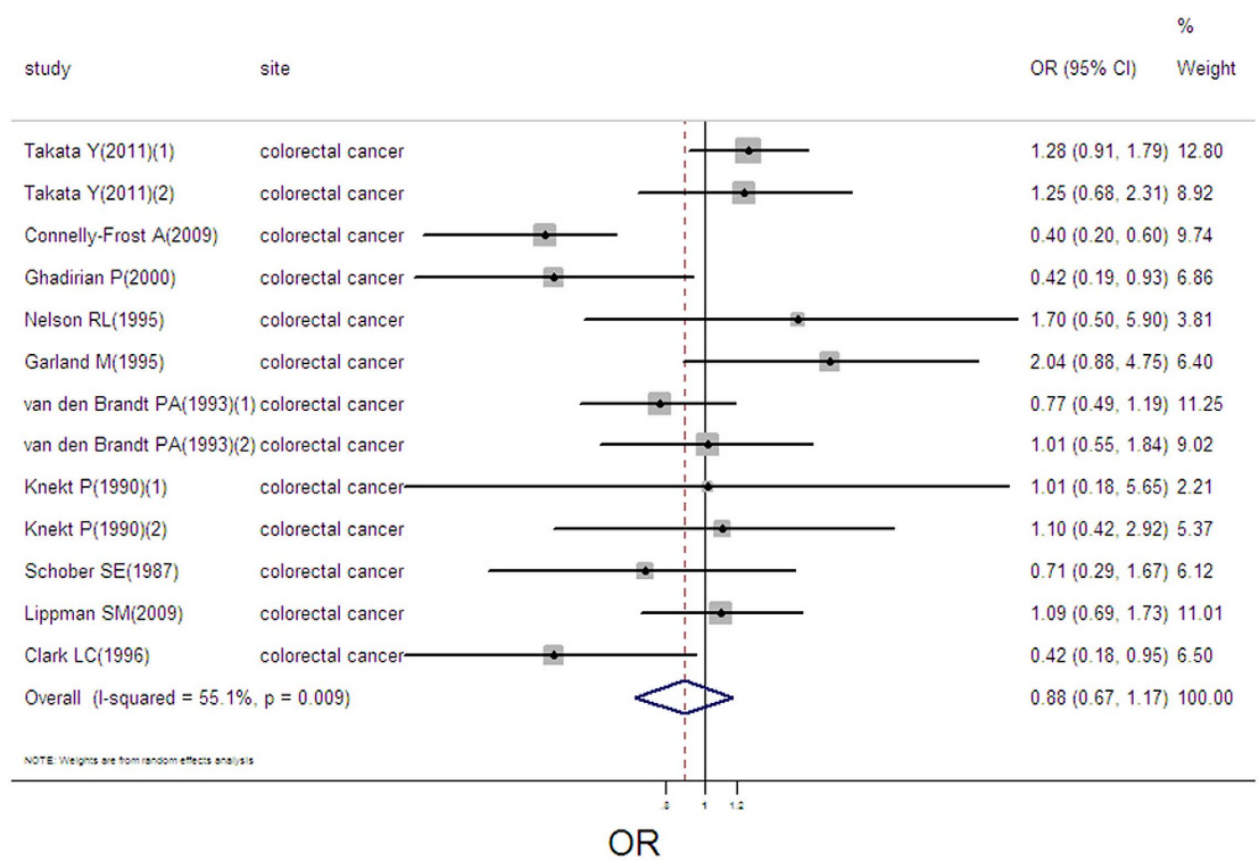

Figure 11. Forest plot of meta-analysis on selenium and colorectal cancer.

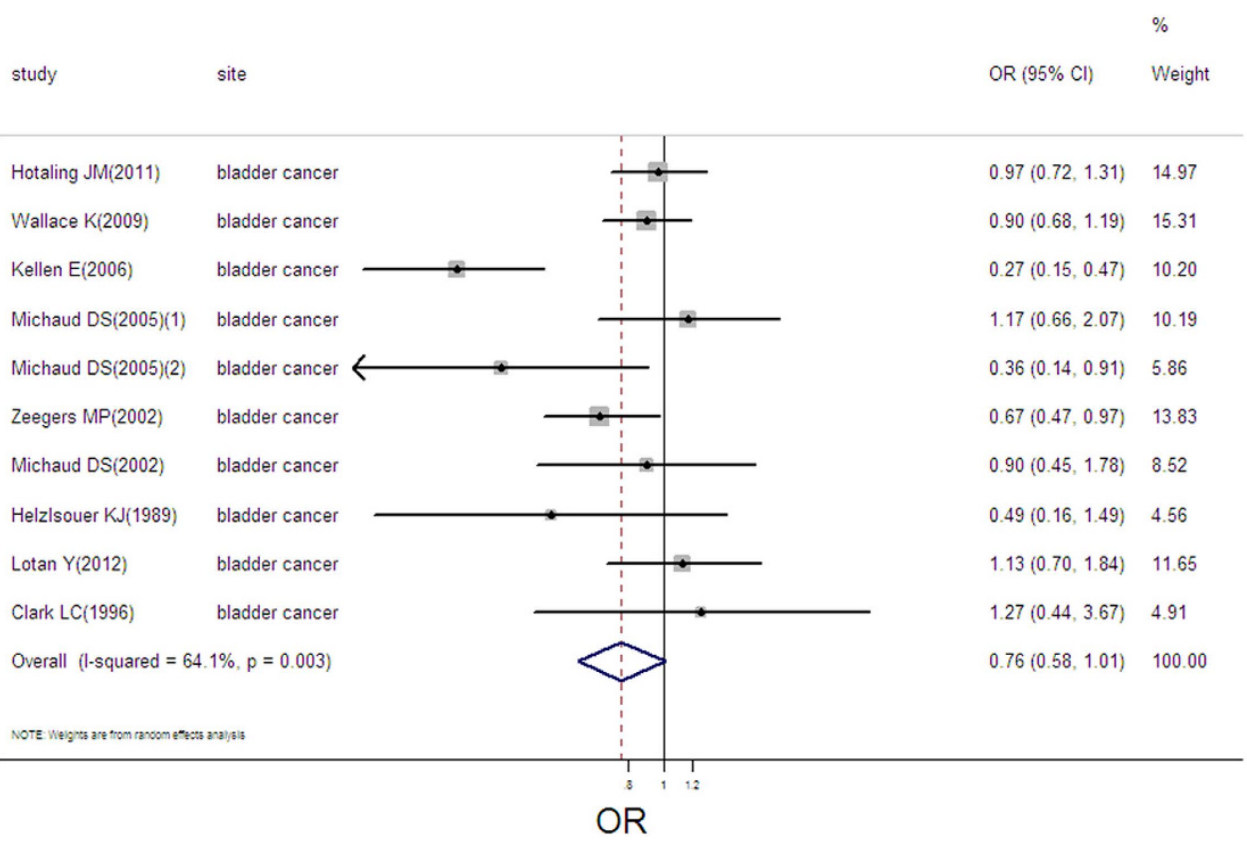

Figure 12. Forest plot of meta-analysis on selenium and bladder cancer.

showed that high selenium exposure was not associated with colorectal cancer (pooled OR $=0.89,95 \% \mathrm{CI}$ : $0.67-1.17$, Fig. 11), with moderate heterogeneity $\left(\mathrm{Q}=26.71, P=0.009 ; I^{2} \%=55.1\right)$, but without publication bias (Begger's test $z_{c}=0.06 ; P=0.951$; Egger's test $t=-0.49, P=0.634$ ). Sensitivity analysis showed that the result was robust (Supplemental Table S1).

Selenium exposure and bladder cancer. 10 estimates from 9 studies were incorporated in the pooled analysis. We found that exposure mode, area and design were not influencing factor (exposure mode: $P=0.05$; area: $P=0.708$; design: $P=0.601)$. Therefore, we took the 10 estimates into meta-analysis. The result showed that high selenium exposure was not associated with bladder cancer (pooled OR $=0.76,95 \% \mathrm{CI}$ : 0.58-1.01, as shown in Fig. 12) with moderate heterogeneity $\left(\mathrm{Q}=25.06, P=0.003 ; I^{2} \%=64.1\right)$, but without publication bias (Begger's test $z_{c}=0.72 ; P=0.474$; Egger's test $\left.t=-0.90, P=0.395\right)$. 3 groups of data were incorporated into dose-response 


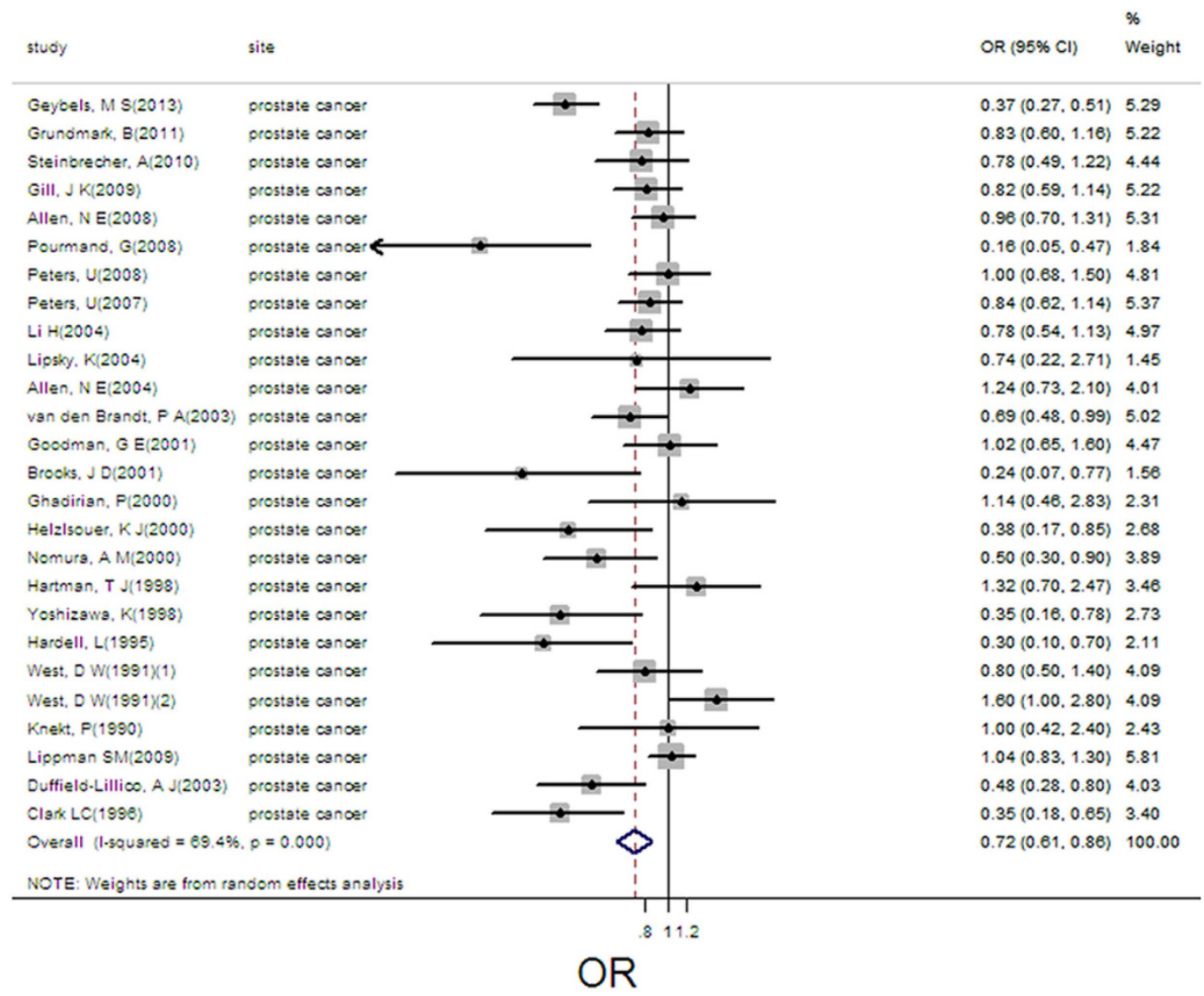

Figure 13. Forest plot of meta-analysis on selenium and prostate cancer.

analysis between toenail selenium and bladder cancer risk. The consequence of linear dose-response analysis presented that toenail selenium was not associated with bladder cancer risk per $0.1 \mathrm{ug} / \mathrm{g}$ increase of toenail selenium (pooled OR $=0.95,95 \%$ CI: 0.90-1.01). Otherwise, we did not find a threshold effect in the plot between toenail selenium and bladder cancer risk in nonlinear dose-response analysis ( $P=0.413$ for non-linearity; Fig. S5)

Selenium exposure and prostate cancer. 26 estimates from 25 studies described the association between selenium and risk of prostate cancer. We found that exposure mode, area and design were not influencing factor (exposure mode: $P=0.682$; area: $P=0.362$; design: $P=0.478$ ). Therefore, we took the 26 estimates into meta-analysis. The result showed that high selenium exposure decreased risk of prostate cancer (pooled $\mathrm{OR}=0.72$, 95\%CI: 0.61-0.86, Fig. 13), with moderate heterogeneity $\left(\mathrm{Q}=81.6, P=0.000 ; I^{2} \%=69.4\right)$. There was no publication bias (Begger's test $z_{c}=1.92 ; P=0.055$; Egger's test $t=-1.90, P=0.070$ ). Sensitivity analysis showed that the result was robust (Supplemental Table S1).

7 groups of data were incorporated into dose-response analysis between plasma/serum selenium and prostate cancer and 5 groups of data were included between toenail selenium and prostate cancer. The result of linear dose-response analysis presented that plasma/serum selenium was associated with prostate cancer risk per $10 \mathrm{ug} / \mathrm{L}$ increases (pooled OR $=0.97,95 \% \mathrm{CI}: 0.95-0.99 ; \mathrm{Q}=19.5, P=0.003$ ). The result presented that toenail selenium was associated with prostate cancer risk per $0.1 \mathrm{ug} / \mathrm{g}$ increases (pooled OR $=0.94,95 \% \mathrm{CI}$ : 0.89-0.99; $\mathrm{Q}=20.27, P=0.000)$. We did not find threshold effects in the plots between plasma/serum and toenail selenium and prostate cancer risk in nonlinear dose-response analyses $(P=0.739, P=0.886$ for non-linearity, respectively; Fig. S6,S7).

Selenium exposure and risk of skin cancer. 6 estimates from 4 studies were incorporated into the pooled analysis. We found that exposure mode and area were not influencing factor (exposure mode: $P=0.395$; area: $P=0.454)$. Therefore, we took the 6 estimates into meta-analysis. The result of the pooled analysis showed that high selenium exposure was not associated with skin cancer (pooled OR $=1.09,95 \%$ CI: 0.98-1.21, Fig. 14), with no heterogeneity $\left(\mathrm{Q}=3.65, P=0.601 ; I^{2} \%=0.0\right)$ and publication bias (Begger's test $z_{c}=0.00 ; P=1.000$; Egger's test $t=0.42, P=0.697)$. Sensitivity analysis showed that the result was robust (Supplemental Table S1).

Other subgroup analysis. The further stratified analysis were conducted by gender and study design. The results indicated that the protective effect of high selenium exposure had no gender difference (as shown in Table 2). When stratified by design, we found the results from observational studies presented the protective effect of selenium on cancer while the results from RCTs indicated null effect (as shown in Table 2). 


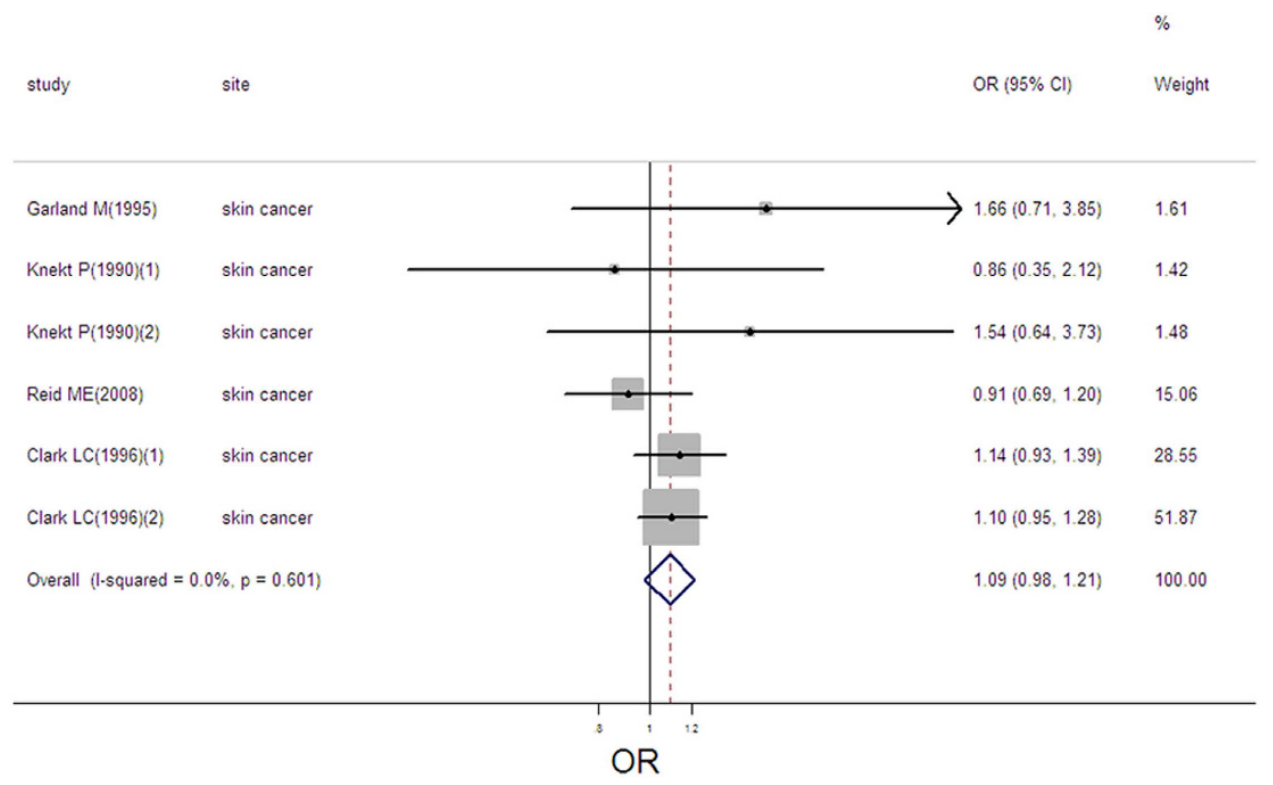

Figure 14. Forest plot of meta-analysis on selenium and skin cancer.

\section{Discussion}

Debating on Se-Cancer association is persistent. Selenium has been hypothesized to be a cancer preventive agent, a cancer therapeutic agent, or be a carcinogen ${ }^{36}$. Several ${ }^{37-41}$ studies presented results that blood selenium was associated with cancer. According to breast cancer, results from Harris H R et al. ${ }^{42}$, Rejali et al. ${ }^{43}$, and Hardell, $\mathrm{L}^{44}$ et al. studies presented a protective effect of selenium, while other observational studies ${ }^{23,24,34,35,45-51}$ showed null associations between selenium and breast cancer. For lung cancer, findings from Jaworska K et al. ${ }^{52}$, Gromadzinska, J et al. ${ }^{53}$, Hartman, T. J et al. ${ }^{54}$, Knekt, P. et al. ${ }^{55}$, van den Brandt, P. A et al. ${ }^{56}$ and Knekt, P et al. ${ }^{24}$ studies showed that high selenium exposure decreased lung cancer risk, but other 6 observational studies $^{24-26,33,57,58}$ did not present similar results. Two randomized controlled trials ${ }^{27,28}$ found that selenium supplement was not associated with lung cancer (HR:1.12; 95\%CI: 0.73-1.72; 0.56; 95\%CI: 0.31-1.01, respectively). Several studies ${ }^{23-26,28-32,59-63}$ described the relation between digest system cancer, but the results were also inconsistent. Stevens, J et al. ${ }^{29}$ study presented that toenail selenium was associated with esophageal squamous cell carcinoma, but not with gastric cardia cancer. Wei WQ et al. ${ }^{30}$ study in China showed that serum selenium was associated with mortality of esophageal squamous cell carcinoma and gastric cardia cancer. Several studies ${ }^{32,60}$ presented null relation between serum selenium and colon cancer, rectal cancer. However, Clark LC et al. ${ }^{28^{\prime}}$ randomized controlled trial showed selenium supplement decreased risk of colorectal cancer in people with skin carcinoma. According to bladder cancer, different studies ${ }^{64-71}$ showed different results. Hotaling JM et al. ${ }^{64}$ study presented that long-term use of supplemental selenium could not decrease bladder cancer risk after 6 years' follow-up. Lotan Y et al. ${ }^{71}$ randomized controlled trial presented a similar result. Michaud, D. S et al. ${ }^{67}$ study showed a gender-specific relation between toenail selenium and bladder cancer that high toenail selenium had a protective effect on female bladder cancer. According to prostate cancer, the US Selenium and Vitamin E Cancer Prevention Trial showed that a long term oral supplement of selenomethionie(200ug/d) did not prevent prostate cancer $^{27}$. And numerous observational studies ${ }^{23,24,72-91}$ also presented inconsistent results. Hurst, R et al. ${ }^{92}$ meta-analysis which included twelve studies showed that prostate cancer risk reduced with the increase of plasma/serum and toenail selenium. The Nutritional Prevention of Cancer Trial (NPCT) ${ }^{28}$ investigated the effect of selenium supplement on the development of skin cancer, and found no protective efficacy, Reid, M. E et al. ${ }^{93}$ study which was a sub-study of NPCT showed a similar result.

The results of meta-analysis suggest an inverse relation between selenium exposure and the total cancer risk (including breast cancer, lung cancer, esophageal cancer, gastric cancer, colorectal cancer, bladder cancer, prostate cancer, skin cancer, not site-specific cancer and other cancer). What is more, the results of dose-response analysis show a downward trend between plasma/serum selenium, toenail selenium and total cancer risk. The biomarker of selenium (serum/plasma and toenail selenium) was associated with cancer risk and could be easily measured and monitored to evaluate people health status. However, our results find that selenium supplement is not associated with cancer risk. Selenium supplement contains either inorganic or organic species or a mixture of both. The SELECT trial uses L-selenomethionie as an oral supplement, while the NPCT trial uses selenium yeast tablets. The different types of selenium supplement may present different effects on human health. On the other hand, first-pass elimination and bioavailability of different participants should be considered. Burk et al. ${ }^{94}$, study presents the results that the full expression of selenoprotein $\mathrm{P}$ requires more Se intake than that required by the full expression of GPxs, indicating that the Se intakes of the current studies are probably inadequate for optimizing the protective effects. We also cannot exclude the possibility that it is what associated with higher biochemical selenium level presents the shielding effect other than selenium exposure itself. We know that RCTs should research the association between selenium supplement and cancer risk, while observational 


\begin{tabular}{|c|c|c|c|c|c|c|}
\hline \multirow[b]{2}{*}{ Subgroup } & \multirow[b]{2}{*}{ Type of subgroup } & \multirow[b]{2}{*}{ No of estimates } & \multirow[b]{2}{*}{ OR(95\%CI) } & \multirow{2}{*}{\begin{tabular}{|c|} 
Homogeneity test \\
$\mathrm{Q}$
\end{tabular}} & \multirow[b]{2}{*}{$P$} & \multirow[b]{2}{*}{$I^{2}(\%)$} \\
\hline & & & & & & \\
\hline \multirow{3}{*}{ Design } & cohort & 40 & $0.75(0.68,0.82)$ & 209.01 & 0.000 & 81.8 \\
\hline & Case-control & 61 & $0.77(0.69,0.86)$ & 162.63 & 0.000 & 63.7 \\
\hline & RCT & 13 & $0.89(0.74,1.08)$ & 31.32 & 0.002 & 61.7 \\
\hline \multirow{3}{*}{ Gender } & Men & 39 & $0.74(0.64,0.86)$ & 111.94 & 0.000 & 66.1 \\
\hline & Women & 31 & $0.90(0.86,0.95)$ & 42.01 & 0.071 & 28.6 \\
\hline & Both combined & 44 & $0.73(0.66,0.80)$ & 260.02 & 0.000 & 83.5 \\
\hline
\end{tabular}

Table 2. The stratified analysis by gender and study design.

studies usually research the relation between the biomarker of selenium and cancer risk. These reasons could be used to explain the inconsonant consequences of our stratified analysis by study design. And Vinceti, $\mathrm{M}^{11}$ et al.' meta-analysis also find the inconsistent results between RCTs and observational studies. Future mechanism studies should pay more attention to the procedure from selenium supplement to biochemical selenium status to figure out the reasons for inconsonant effects of selenium supplement and biochemical selenium for preventing cancer. And future epidemiological studies and intervention trials should try to research selenium supplement, plasma/serum selenium and toenail selenium at the same time to reduce the potential bias.

We also find that selenium has diverse effects on specific types of cancer. According to breast cancer, we find an inverse relation when taking all relevant estimates into account. Nonetheless, we lack sufficient data to conduct dose-response analyses. According to lung cancer, we find that high selenium exposure presents a protective efficacy. Though a downward trend is seen in the nonlinear dose-response analysis, there is no statistical significance between plasma/serum selenium and lung cancer risk in linear dose-response analysis. The association between lung cancer and selenium exposure needs more discussion. According to esophageal cancer and gastric cancer, we find an obvious inverse relation. The quantity of estimates included in meta-analyses is not as many as other types of cancer, and we lack sufficient data to conduct dose-response analyses. According to colorectal cancer, we find no association between selenium exposure and cancer risk. Nevertheless, Ou Y et al. ${ }^{95}$ meta-analysis which included seven studies showed a protective effect of selenium on colorectal adenomas $(\mathrm{OR}=0.67 ; 95 \% \mathrm{CI}: 0.55-81)$. Selenium exposure probably plays a protective role in colorectal benign tumor rather than cancer, and the results need more researches. According to bladder cancer, we find no statistical significance between selenium exposure and bladder cancer. However, Amaral A F et al. ${ }^{96}$ meta-analysis which included seven epidemiologic studies presents that plasma/serum selenium and toenail selenium have protective effects on bladder cancer risk. According to prostate cancer, we find a protective effect of high selenium exposure for prostate cancer. The results of linear dose-response analyses between plasma/serum selenium, toenail selenium and prostate cancer support the result, and downward trends are shown in nonlinear dose-response analyses. However, two randomized controlled trials (the NPCT trial ${ }^{28}$ and the SELECT trial ${ }^{27}$ ) focusing on selenium supplement present the consequence that selenium supplement is not associated with prostate cancer risk. According to skin cancer, we find selenium is not associated with skin cancer risk.

There are numerous hypotheses about the potential anticarcinogenic mechanisms of selenium. The major positive effect may be contributed by the antioxidant function of GPxs and selenoprotein $\mathrm{P}^{94}$. Selenium is associated with the regulation of protein folding via the function of the endoplasmic reticulum to influence the process of necrosis and apoptosis of malignant cells ${ }^{97,98}$. Selenium also has the effect on DNA stability ${ }^{98}$. However, different malignant cells have their special biological characteristics and microenvironment for progress and invasion. They probably have disparate abilities of utilizing selenium. Hence, selenium probably has no effect on some types of cancer. The exact mechanism has yet to be investigated. On the other hand, the adverse effects of selenium supplement: mainly diabetes ${ }^{27,99}$, glaucoma ${ }^{28}$, and dermatologic alterations ${ }^{27}$ could not be ignored. So we should try to clarify what level of selenium supplement is needed for adequate nutrition and at what level dose is "unsafe".

Our meta-analysis has several limitations clearly. Measurement errors in the assessment of selenium exposure may bias the effect estimates. Even among those studies regarding the same biochemical selenium as exposure, different measurement methods, different facilities and different staffs are all easy to produce measurement errors, and it is hard to make corrections. As showed in our inclusion criteria, we select case-control studies, cohort studies and RCTs into our meta-analysis. Selenium exposure may be linked to other behaviors like age, income, race, smoking status, alcohol consumption, body mass index, physical activity. These controlled confounding factors differ among sixty-nine studies and may influence the association between selenium exposure and cancer risk. Because of the insufficient number of relevant estimates, we have limited power to conduct subgroup analysis of pathological types of different cancer, and other controlled confounding factors.

Our study also has a few strength. We bring in a large number of studies and have largely avoided some main influencing factors by meta-regression analyses. And the robust outcomes of sensitivity analysis suggest that there is no distinct date making particularly contribution to the results. We detect the association between selenium exposure and different types of cancer to find a comprehensive understanding from global effects to local effects. We also conduct linear dose-response analyses which are stricter than high-versus-low analysis and the results of nonlinear dose-response analyses show dose-response trends in plots which are visual and accessible.

\section{Conclusions}

High selenium exposure could decrease cancer risk, especially high plasma/serum selenium and toenail selenium. High selenium exposure may have dissimilar effects on specific types of cancer. Future epidemiological studies 
and intervention trials should try to research selenium supplement, plasma/serum selenium and toenail selenium at the same time to reduce the potential bias. The exact mechanism needs to be further investigated.

\section{References}

1. Roman, M., Jitaru, P. \& Barbante, C. Selenium Biochemistry and its Role for Human Health. Metallomics. 6,25-54 (2013).

2. Rayman, M. P. Selenium and Human Health. Lancet. 379, 1256-1268 (2012).

3. Tanguy, S., Grauzam, S., de Leiris, J. \& Boucher, F. Impact of Dietary Selenium Intake On Cardiac Health: Experimental Approaches and Human Studies. Mol Nutr Food Res. 56, 1106-1121 (2012).

4. Berthold, H. K., Michalke, B., Krone, W., Guallar, E. \& Gouni-Berthold, I. Influence of Serum Selenium Concentrations On Hypertension: The Lipid Analytic Cologne Cross-Sectional Study. J Hypertens. 30, 1328-1335 (2012).

5. Rees, K. et al. Selenium Supplementation for the Primary Prevention of Cardiovascular Disease. Cochrane Database Syst Rev. 1, D9671 (2013).

6. Vinceti, M. et al. Cerebrospinal Fluid of Newly Diagnosed Amyotrophic Lateral Sclerosis Patients Exhibits Abnormal Levels of Selenium Species Including Elevated Selenite. Neurotoxicology. 38, 25-32 (2013).

7. Park, K. et al. Toenail Selenium and Incidence of Type 2 Diabetes in U.S. Men and Women. Diabetes Care. 35, 1544-1551 (2012).

8. Stranges, S. et al. A Prospective Study of Dietary Selenium Intake and Risk of Type 2 Diabetes. BMC Public Health. 10, 564 (2010).

9. Bleys, J., Navas-Acien, A. \& Guallar, E. Serum Selenium and Diabetes in U.S. Adults. Diabetes Care. 30, 829-834 (2007).

10. Rajpathak, S., Rimm, E., Morris, J. S. \& Hu, F. Toenail Selenium and Cardiovascular Disease in Men with Diabetes. J Am Coll Nutr. 24, 250-256 (2005)

11. Vinceti, M. et al. Selenium for Preventing Cancer. Cochrane Database Syst Rev. 3, D5195 (2014)

12. Stang, A. Critical Evaluation of the Newcastle-Ottawa Scale for the Assessment of the Quality of Nonrandomized Studies in MetaAnalyses. Eur J Epidemiol. 25, 603-605 (2010).

13. Wells, G. A. \& B. S. D. O. The Newcastle-Ottawa Scale (NOS) for Assessing the Quality of Nonrandomised Studies in Meta-Analyses. Secondary the Newcastle-Ottawa Scale (NOS) for Assessing the Quality of Nonrandomised Studies in Meta-Analyses. (2011) Http:// Www.Ohri.Ca/Programs/Clinical_Epidemiology/Oxford.Asp. (2014-03-10).

14. Higgins, J. P. \& Green, S. Cochrane Handbook for Systematic Reviews of Interventions Version5.1.0 [Updated March 2011]. (2011) http://handbook.cochrane.org/. (2014-03-12).

15. Greenland, S. \& Longnecker, M. P. Methods for Trend Estimation From Summarized Dose-Response Data, with Applications to Meta-Analysis. Am J Epidemiol. 135, 1301-1309 (1992).

16. Orsini, N., Li, R., Wolk, A., Khudyakov, P. \& Spiegelman, D. Meta-Analysis for Linear and Nonlinear Dose-Response Relations: Examples, an Evaluation of Approximations, and Software. Am J Epidemiol. 175, 66-73 (2012).

17. Higgins, J. P. \& Thompson, S. G. Quantifying Heterogeneity in a Meta-Analysis. Stat Med. 21, 1539-1558 (2002).

18. Higgins, J. P., Thompson, S. G., Deeks, J. J. \& Altman, D. G. Measuring Inconsistency in Meta-Analyses. BMJ. 327, 557-560 (2003).

19. Mantel, N. \& Haenszel, W. Statistical Aspects of the Analysis of Data From Retrospective Studies of Disease. J Natl Cancer Inst. 22, 719-748 (1959)

20. DerSimonian, R. \& Laird, N. Meta-Analysis in Clinical Trials. Control Clin Trials. 7, 177-188 (1986).

21. Begg, C. B. \& Mazumdar, M. Operating Characteristics of a Rank Correlation Test for Publication Bias. Biometrics. 50, 1088-1101 (1994).

22. Egger, M. \& Smith, G. D. Bias in Location and Selection of Studies. BMJ. 316, 61-66 (1998).

23. Ghadirian, P. et al. A Case-Control Study of Toenail Selenium and Cancer of the Breast, Colon, and Prostate. Cancer Detect Prev. 24, 305-313 (2000).

24. Knekt, P. et al. Serum Selenium and Subsequent Risk of Cancer Among Finnish Men and Women. J Natl Cancer Inst. 82, 864-868 (1990).

25. Garland, M. et al. Prospective Study of Toenail Selenium Levels and Cancer Among Women. J Natl Cancer Inst. 87, 497-505 (1995).

26. Kabuto, M. et al. Prediagnostic Serum Selenium and Zinc Levels and Subsequent Risk of Lung and Stomach Cancer in Japan. Cancer Epidemiol Biomarkers Prev. 3, 465-469 (1994).

27. Lippman, S. M. et al. Effect of Selenium and Vitamin E On Risk of Prostate Cancer and Other Cancers: The Selenium and Vitamin E Cancer Prevention Trial (SELECT). JAMA. 301, 39-51 (2009).

28. Clark, L. C. et al. Effects of Selenium Supplementation for Cancer Prevention in Patients with Carcinoma of the Skin. A Randomized Controlled Trial. Nutritional Prevention of Cancer Study Group. JAMA. 276, 1957-1963 (1996).

29. Steevens, J., van den Brandt, P. A., Goldbohm, R. A. \& Schouten, L. J. Selenium Status and the Risk of Esophageal and Gastric Cancer Subtypes: The Netherlands Cohort Study. Gastroenterology. 138, 1704-1713 (2010).

30. Wei, W. Q. et al. Prospective Study of Serum Selenium Concentrations and Esophageal and Gastric Cardia Cancer, Heart Disease, Stroke, and Total Death. Am J Clin Nutr. 79, 80-85 (2004).

31. Mark, S. D. et al. Prospective Study of Serum Selenium Levels and Incident Esophageal and Gastric Cancers. J Natl Cancer Inst. 92 , 1753-1763 (2000).

32. van den Brandt, P. A. et al. A Prospective Cohort Study On Toenail Selenium Levels and Risk of Gastrointestinal Cancer. J Natl Cancer Inst. 85, 224-229 (1993).

33. Goodman, G. E., Schaffer, S., Bankson, D. D., Hughes, M. P. \& Omenn, G. S. Predictors of Serum Selenium in Cigarette Smokers and the Lack of Association with Lung and Prostate Cancer Risk. Cancer Epidemiol Biomarkers Prev. 10, 1069-1076 (2001).

34. Cui, Y., Vogt, S., Olson, N., Glass, A. G. \& Rohan, T. E. Levels of Zinc, Selenium, Calcium, and Iron in Benign Breast Tissue and Risk of Subsequent Breast Cancer. Cancer Epidemiol Biomarkers Prev. 16, 1682-1685 (2007).

35. van T, V. P., van der Wielen, R. P., Kok, F. J., Hermus, R. J. \& Sturmans, F. Selenium in Diet, Blood, and Toenails in Relation to Breast Cancer: A Case-Control Study. Am J Epidemiol. 131, 987-994 (1990).

36. Vinceti, M., Crespi, C. M., Malagoli, C., Del, G. C. \& Krogh, V. Friend Or Foe? The Current Epidemiologic Evidence On Selenium and Human Cancer Risk. J Environ Sci Health C Environ Carcinog Ecotoxicol Rev. 31, 305-341 (2013).

37. Bleys, J., Navas-Acien, A. \& Guallar, E. Serum Selenium Levels and All-Cause, Cancer, and Cardiovascular Mortality Among US Adults. Arch Intern Med. 168, 404-410 (2008).

38. Akbaraly, N. T. et al. Selenium and Mortality in the Elderly: Results From the EVA Study. Clin Chem. 51, 2117-2123 (2005).

39. Kornitzer, M., Valente, F., De Bacquer, D. \& Neve, J. \& De Backer, G. Serum Selenium and Cancer Mortality: A Nested Case-Control Study within an Age- and Sex-Stratified Sample of the Belgian Adult Population. Eur J Clin Nutr. 58, 98-104 (2004).

40. Ujiie, S. \& Kikuchi, H. The Relation Between Serum Selenium Value and Cancer in Miyagi, Japan: 5-Year Follow Up Study. Tohoku J Exp Med. 196, 99-109 (2002).

41. Persson-Moschos, M. E., Stavenow, L., Akesson, B. \& Lindgarde, F. Selenoprotein P in Plasma in Relation to Cancer Morbidity in Middle-Aged Swedish Men. Nutr Cancer. 36, 19-26 (2000)

42. Harris, H. R., Bergkvist, L. \& Wolk, A. Selenium Intake and Breast Cancer Mortality in a Cohort of Swedish Women. Breast Cancer Res Treat. 134, 1269-1277 (2012).

43. Rejali, L., Jaafar, M. H. \& Ismail, N. H. Serum Selenium Level and Other Risk Factors for Breast Cancer Among Patients in a Malaysian Hospital. Environ Health Prev Med. 12, 105-110 (2007). 
44. Hardell, L. et al. Levels of Selenium in Plasma and Glutathione Peroxidase in Erythrocytes and the Risk of Breast Cancer. A CaseControl Study. Biol Trace Elem Res. 36, 99-108 (1993).

45. Pan, S. Y., Zhou, J., Gibbons, L., Morrison, H. \& Wen, S. W. Antioxidants and Breast Cancer Risk- a Population-Based Case-Control Study in Canada. Bmc Cancer. 11, 372 (2011).

46. Singh, P., Kapil, U., Shukla, N. K., Deo, S. \& Dwivedi, S. N. Association Between Breast Cancer and Vitamin C, Vitamin E and Selenium Levels: Results of a Case-Control Study in India. Asian Pac J Cancer Prev. 6, 177-180 (2005).

47. Mannisto, S. et al. Toenail Selenium and Breast Cancer-A Case-Control Study in Finland. Eur J Clin Nutr. 54, 98-103 (2000).

48. Dorgan, J. F. et al. Relationships of Serum Carotenoids, Retinol, Alpha-Tocopherol, and Selenium with Breast Cancer Risk: Results From a Prospective Study in Columbia, Missouri (United States). Cancer Causes Control. 9, 89-97 (1998).

49. Strain, J. J. et al. Thyroid Hormones and Selenium Status in Breast Cancer. Nutr Cancer. 27, 48-52 (1997).

50. van T, V. P. et al. Tissue Antioxidants and Postmenopausal Breast Cancer: The European Community Multicentre Study On Antioxidants, Myocardial Infarction, and Cancer of the Breast (EURAMIC). Cancer Epidemiol Biomarkers Prev. 5, 441-447 (1996).

51. van den Brandt, P. A. et al. Toenail Selenium Levels and the Risk of Breast Cancer. Am J Epidemiol. 140, 20-26 (1994).

52. Jaworska, K. et al. A Low Selenium Level is Associated with Lung and Laryngeal Cancers. Plos One. 8, e59051 (2013).

53. Gromadzinska, J., Wasowicz, W., Rydzynski, K. \& Szeszenia-Dabrowska, N. Oxidative-Stress Markers in Blood of Lung Cancer Patients Occupationally Exposed to Carcinogens. Biol Trace Elem Res. 91, 203-215 (2003).

54. Hartman, T. J. et al. Toenail Selenium Concentration and Lung Cancer in Male Smokers (Finland). Cancer Causes Control. 13, 923-928 (2002).

55. Knekt, P., Marniemi, J., Teppo, L., Heliovaara, M. \& Aromaa, A. Is Low Selenium Status a Risk Factor for Lung Cancer? Am J Epidemiol. 148, 975-982 (1998).

56. van den Brandt, P. A. et al. A Prospective Cohort Study On Selenium Status and the Risk of Lung Cancer. Cancer Res. 53, 4860-4865 (1993).

57. Jablonska, E., Gromadzinska, J., Sobala, W., Reszka, E. \& Wasowicz, W. Lung Cancer Risk Associated with Selenium Status is Modified in Smoking Individuals by Sep15 Polymorphism. Eur J Nutr. 47, 47-54 (2008).

58. Ratnasinghe, D. et al. Serum Tocopherols, Selenium and Lung Cancer Risk Among Tin Miners in China. Cancer Causes Control. 11, 129-135 (2000).

59. Cai, L. et al. Dietary Selenium Intake, Aldehyde Dehydrogenase-2 and X-ray Repair Cross-Complementing 1 Genetic Polymorphisms, and the Risk of Esophageal Squamous Cell Carcinoma. Cancer-Am Cancer Soc. 106, 2345-2354 (2006).

60. Takata, Y. et al. Serum Selenium, Genetic Variation in Selenoenzymes, and Risk of Colorectal Cancer: Primary Analysis From the Women's Health Initiative Observational Study and Meta-Analysis. Cancer Epidemiol Biomarkers Prev. 20, 1822-1830 (2011).

61. Connelly-Frost, A. et al. Selenium, Folate, and Colon Cancer. Nutr Cancer. 61, 165-178 (2009).

62. Nelson, R. L. et al. Serum Selenium and Colonic Neoplastic Risk. Dis Colon Rectum. 38, 1306-1310 (1995).

63. Schober, S. E. et al. Serologic Precursors of Cancer. I. Prediagnostic Serum Nutrients and Colon Cancer Risk. Am J Epidemiol. 126, 1033-1041 (1987).

64. Hotaling, J. M. et al. Long-Term Use of Supplemental Vitamins and Minerals Does Not Reduce the Risk of Urothelial Cell Carcinoma of the Bladder in the Vitamins and Lifestyle Study. J Urol. 185, 1210-1215 (2011).

65. Wallace, K. et al. Selenium and Risk of Bladder Cancer: A Population-Based Case-Control Study. Cancer Prev Res (Phila). 2, 70-73 (2009).

66. Kellen, E., Zeegers, M. \& Buntinx, F. Selenium is Inversely Associated with Bladder Cancer Risk: A Report From the Belgian CaseControl Study On Bladder Cancer. Int J Urol. 13, 1180-1184 (2006).

67. Michaud, D. S., De Vivo, I., Morris, J. S. \& Giovannucci, E. Toenail Selenium Concentrations and Bladder Cancer Risk in Women and Men. Br J Cancer. 93, 804-806 (2005).

68. Zeegers, M. P., Goldbohm, R. A., Bode, P. \& van den Brandt, P. A. Prediagnostic Toenail Selenium and Risk of Bladder Cancer. Cancer Epidemiol Biomarkers Prev. 11, 1292-1297 (2002).

69. Michaud, D. S. et al. No Association Between Toenail Selenium Levels and Bladder Cancer Risk. Cancer Epidemiol Biomarkers Prev. 11, 1505-1506 (2002).

70. Helzlsouer, K. J., Comstock, G. W. \& Morris, J. S. Selenium, Lycopene, Alpha-Tocopherol, Beta-Carotene, Retinol, and Subsequent Bladder Cancer. Cancer Res. 49, 6144-6148 (1989).

71. Lotan, Y. et al. Evaluation of Vitamin E and Selenium Supplementation for the Prevention of Bladder Cancer in SWOG Coordinated SELECT. J Urol. 187, 2005-2010 (2012).

72. Geybels, M. S., Verhage, B. A., van Schooten, F. J., Goldbohm, R. A. \& van den Brandt, P. A. Advanced Prostate Cancer Risk in Relation to Toenail Selenium Levels. J Natl Cancer Inst. 105, 1394-1401 (2013).

73. Grundmark, B., Zethelius, B., Garmo, H. \& Holmberg, L. Serum Levels of Selenium and Smoking Habits at Age 50 Influence Long Term Prostate Cancer Risk; A 34 Year ULSAM Follow-Up. Bmc Cancer. 11, 431 (2011).

74. Steinbrecher, A. et al. Effects of Selenium Status and Polymorphisms in Selenoprotein Genes On Prostate Cancer Risk in a Prospective Study of European Men. Cancer Epidemiol Biomarkers Prev. 19, 2958-2968 (2010).

75. Gill, J. K. et al. Association of Selenium, Tocopherols, Carotenoids, Retinol, and 15-Isoprostane F(2t) in Serum Or Urine with Prostate Cancer Risk: The Multiethnic Cohort. Cancer Causes Control. 20, 1161-1171 (2009).

76. Allen, N. E. et al. Plasma Selenium Concentration and Prostate Cancer Risk: Results From the European Prospective Investigation Into Cancer and Nutrition (EPIC). Am J Clin Nutr. 88, 1567-1575 (2008).

77. Pourmand, G. et al. Serum Selenium Level and Prostate Cancer: A Case-Control Study. Nutr Cancer. 60, 171-176 (2008).

78. Peters, U. et al. Vitamin E and Selenium Supplementation and Risk of Prostate Cancer in the Vitamins and Lifestyle (VITAL) Study Cohort. Cancer Causes Control. 19, 75-87 (2008).

79. Peters, U. et al. Serum Selenium and Risk of Prostate Cancer-A Nested Case-Control Study. Am J Clin Nutr. 85, 209-217 (2007).

80. Li, H. et al. A Prospective Study of Plasma Selenium Levels and Prostate Cancer Risk. J Natl Cancer Inst. 96, 696-703 (2004).

81. Lipsky, K. et al. Selenium Levels of Patients with Newly Diagnosed Prostate Cancer Compared with Control Group. Urology. 63, 912-916 (2004).

82. Allen, N. E., Morris, J. S., Ngwenyama, R. A. \& Key, T. J. A Case-Control Study of Selenium in Nails and Prostate Cancer Risk in British Men. Br J Cancer. 90, 1392-1396 (2004).

83. van den Brandt, P. A., Zeegers, M. P., Bode, P. \& Goldbohm, R. A. Toenail Selenium Levels and the Subsequent Risk of Prostate Cancer: A Prospective Cohort Study. Cancer Epidemiol Biomarkers Prev. 12, 866-871 (2003).

84. Duffield-Lillico, A. J. et al. Selenium Supplementation, Baseline Plasma Selenium Status and Incidence of Prostate Cancer: An Analysis of the Complete Treatment Period of the Nutritional Prevention of Cancer Trial. Bju Int. 91, 608-612 (2003).

85. Brooks, J. D. et al. Plasma Selenium Level Before Diagnosis and the Risk of Prostate Cancer Development. J Urol. 166, 2034-2038 (2001).

86. Helzlsouer, K. J. et al. Association Between Alpha-Tocopherol, Gamma-Tocopherol, Selenium, and Subsequent Prostate Cancer. J Natl Cancer Inst. 92, 2018-2023 (2000).

87. Nomura, A. M., Lee, J., Stemmermann, G. N. \& Combs, G. J. Serum Selenium and Subsequent Risk of Prostate Cancer. Cancer Epidemiol Biomarkers Prev. 9, 883-887 (2000).

88. Hartman, T. J. et al. The Association Between Baseline Vitamin E, Selenium, and Prostate Cancer in the Alpha-Tocopherol, BetaCarotene Cancer Prevention Study. Cancer Epidemiol Biomarkers Prev. 7, 335-340 (1998). 
89. Yoshizawa, K. et al. Study of Prediagnostic Selenium Level in Toenails and the Risk of Advanced Prostate Cancer. J Natl Cancer Inst. 90, 1219-1224 (1998).

90. Hardell, L., Degerman, A., Tomic, R., Marklund, S. L. \& Bergfors, M. Levels of Selenium in Plasma and Glutathione Peroxidase in Erythrocytes in Patients with Prostate Cancer Or Benign Hyperplasia. Eur J Cancer Prev. 4, 91-95 (1995).

91. West, D. W., Slattery, M. L., Robison, L. M., French, T. K. \& Mahoney, A. W. Adult Dietary Intake and Prostate Cancer Risk in Utah: A Case-Control Study with Special Emphasis On Aggressive Tumors. Cancer Causes Control. 2, 85-94 (1991).

92. Hurst, R. et al. Selenium and Prostate Cancer: Systematic Review and Meta-Analysis. Am J Clin Nutr. 96, 111-122 (2012).

93. Reid, M. E. et al. The Nutritional Prevention of Cancer: 400 Mcg Per Day Selenium Treatment. Nutr Cancer. 60, 155-163 (2008).

94. Burk, R. F., Hill, K. E. \& Motley, A. K. Selenoprotein Metabolism and Function: Evidence for More than One Function for Selenoprotein P. J NUTR. 133, 1517S-1520S (2003).

95. Ou, Y., Jiang, B., Wang, X., Ma, W. \& Guo, J. Selenium and Colorectal Adenomas Risk: A Meta-Analysis. Nutr Cancer. 64, 1153-1159 (2012).

96. Amaral, A. F., Cantor, K. P., Silverman, D. T. \& Malats, N. Selenium and Bladder Cancer Risk: A Meta-Analysis. Cancer Epidemiol Biomarkers Prev. 19, 2407-2415 (2010).

97. Korotkov, K. V., Kumaraswamy, E., Zhou, Y., Hatfield, D. L. \& Gladyshev, V. N. Association Between the 15-kDa Selenoprotein and UDP-glucose: Glycoprotein Glucosyltransferase in the Endoplasmic Reticulum of Mammalian Cells. J Biol Chem. 276, 15330-15336 (2001).

98. Whanger, P. D. Selenium and its Relationship to Cancer: An Update. Br J Nutr. 91, 11-28 (2004).

99. Stranges, S. et al. Effects of Long-Term Selenium Supplementation On the Incidence of Type 2 Diabetes: A Randomized Trial. Ann Intern Med. 147, 217-223 (2007).

\section{Acknowledgements}

This research was supported by the Soft Science Key Project of the Science and Technology Department of Zhejiang Province (2015C25027), the Medical Health Scientific Research Fund Project of Zhejiang Province (2015KYA070), and Zhejiang University Undergraduate Zetetic Experiment Project of Public Health (2013).

\section{Author Contributions}

X.C. and C.W. conducted the search work and all the data were extracted independently by X.C., C.W. and N.S. X.C. and C.W. wrote the main manuscript text and prepared the tables. N.S.,W.Y., W.F., S.W. and P.W. prepared figures. X.L. reviewed and corrected the manuscript. F.W. reviewed the manuscript.

\section{Additional Information}

Supplementary information accompanies this paper at http://www.nature.com/srep

Competing financial interests: The authors declare no competing financial interests.

How to cite this article: Cai, X. et al. Selenium Exposure and Cancer Risk: an Updated Meta-analysis and Metaregression. Sci. Rep. 6, 19213; doi: 10.1038/srep19213 (2016).

(c) (i) This work is licensed under a Creative Commons Attribution 4.0 International License. The images or other third party material in this article are included in the article's Creative Commons license, unless indicated otherwise in the credit line; if the material is not included under the Creative Commons license, users will need to obtain permission from the license holder to reproduce the material. To view a copy of this license, visit http://creativecommons.org/licenses/by/4.0/ 